\title{
Nuclear Magnetic Resonance with Fast Field-Cycling Setup: A Valid Tool for Soil Quality Investigation
}

\author{
Pellegrino Conte ${ }^{1, *(1)}$ and Paolo Lo Meo ${ }^{2}$ (i) \\ 1 Department of Agricultural, Food and Forest Sciences (SAAF), University of Palermo, 90128 Palermo, Italy \\ 2 Department of Biological, Chemical and Pharmaceutical Sciences and Technologies (STEBICEF), \\ University of Palermo, 90128 Palermo, Italy; paolo.lomeo@unipa.it \\ * Correspondence: pellegrino.conte@unipa.it
}

Received: 22 June 2020; Accepted: 16 July 2020; Published: 18 July 2020

\begin{abstract}
Nuclear magnetic resonance (NMR) techniques are largely employed in several fields. As an example, NMR spectroscopy is used to provide structural and conformational information on pure systems, while affording quantitative evaluation on the number of nuclei in a given chemical environment. When dealing with relaxation, NMR allows understanding of molecular dynamics, i.e., the time evolution of molecular motions. The analysis of relaxation times conducted on complex liquid-liquid and solid-liquid mixtures is directly related to the nature of the interactions among the components of the mixture. In the present review paper, the peculiarities of low resolution fast field-cycling (FFC) NMR relaxometry in soil science are reported. In particular, the general aspects of the typical FFC NMR relaxometry experiment are firstly provided. Afterwards, a discussion on the main mathematical models to be used to "read" and interpret experimental data on soils is given. Following this, an overview on the main results in soil science is supplied. Finally, new FFC NMR-based hypotheses on nutrient dynamics in soils are described
\end{abstract}

Keywords: NMR; relaxometry; fast field cycling; FFC NMR; longitudinal relaxation time; $T_{1}$; soil; soil quality evaluation; soil analysis; environment

\section{Introduction}

The locution "nuclear magnetic resonance", also indicated with the acronym NMR, refers to a multifaceted technique which can be applied to liquid [1], semisolid [2], solid [3], and gas [4] phases. It can be used to unveil not only the structure of pure chemical compounds [5], but also the chemical complexity of mixtures [6], as well as that of living organisms [7,8].

Notwithstanding the vast areas of expertise covered by the NMR techniques and their different aspects related to sample preparation, instrumentation, and targeted results, all of them share the same principles [9]. In general, an ensemble of nuclei-each with magnetic properties distributed into different energy levels described by the orientation of their magnetic moments with respect to an applied magnetic field $\left(\boldsymbol{B}_{\mathbf{0}}\right)$ - are perturbated by an electromagnetic radiation pulse $\left(\boldsymbol{B}_{\mathbf{1}}\right)$ applied for a short time interval along a direction perpendicular to $\boldsymbol{B}_{\mathbf{0}}$. This causes a transfer of energy quanta and an induction of phase coherence in the ensemble. The excited nuclei then return to the ground state via two different relaxation processes. The first one, also referred to as longitudinal relaxation, refers to the regaining of the magnetization equilibrium in the direction of $\boldsymbol{B}_{\mathbf{0}}$ with the loss of energy quanta. The second process, indicated as transverse relaxation, is related to the loss of phase coherence and to the decay of the excited magnetization in the direction perpendicular to $\boldsymbol{B}_{\mathbf{0}}$. Both processes contribute to the overall regaining of the magnetization equilibrium. The time constant associated to the longitudinal relaxation is indicated as $T_{1}$ (also referred to as the longitudinal 
relaxation time), while the time constant of the transverse relaxation is indicated with $T_{2}$ (also referred to as the transverse relaxation time).

The signals acquired by nuclear magnetic resonance are time dependent and can be handled in many ways. As an example, the application of the Fourier transform generates plots (also named spectra) where resonance signals are reported versus frequency. According to the number of frequency axes, it is possible to distinguish among mono- (1D), bi- (2D) and three-dimensional (3D) NMR spectroscopy [10]. The disposition of the resonance signals in the spectra (named chemical shift) as well as their splitting (due to the spin-spin interactions) are strongly dependent on the chemical environment of each nucleus. Moreover, the intensity of the signals depends on the number of nuclei producing that signal. For this reason, the NMR spectra can be used not only to elucidates structure and three-dimensional conformation of pure compounds, but also to quantify how many resonating nuclei are in each chemical environment. However, when a complex mixture is analyzed, quantification may be limited by the nature of the sample phase, the type of pulse sequence used for the NMR investigation, and hardware constraints [3,11,12].

The time scale of the relaxing nuclei is affected by the molecular size, and by the physical state of the system under investigation. As it will be explained below, the relaxation mechanisms involve local magnetic fields (generated by the electronic and atomic environments) modulated by molecular motions. When the Larmor frequency of the local magnetic fields is in resonance with that of the observed nuclei, relaxation occurs. Once the NMR experiments are set to measure relaxation times (either $T_{1}$ or $T_{2}$ ), the time dependent resonance signals can be handled with the inverse Laplace transform to produce relaxograms (either 1D or 2D), where distribution of relaxation times are represented [13-17]. This technique, named time-domain (TD) NMR, is applied to obtain information on molecular dynamics either for simple systems or complex mixtures [18].

Since the end of the seventies of the twentieth century, a new NMR technique has been emerging [19]. It is based on the analysis of the behavior of complex systems when the strength of the applied magnetic field is quickly changed. The technique, named fast field-cycling (FFC) NMR relaxometry, aims at the evaluation of the molecular motions included in the time scale ranging between $10^{-8}$ to $10^{-3} \mathrm{~s}$ [20].

Notwithstanding the term "relaxometry" is generally used when both $T_{1}$ and $T_{2}$ are accounted for [21-23], it is noteworthy that it must be referred only to the contexts where $T_{1}$ values are evaluated [20]. Therefore, FFC NMR relaxometry is intended as the technique by which the $T_{1}$ values are monitored when the strength of the applied magnetic field is varied within a given proton Larmor frequency interval.

Figure 1 shows the time intervals for the molecular motions investigated by applying the corresponding proton Larmor frequencies on the top side of the scale. In particular, molecular tumbling occurs in the time scale $<10^{-7} \mathrm{~s}$ (corresponding to proton Larmor frequencies as large as $10^{7} \mathrm{~Hz}$ ), internal motions occur on a time scale comprised between $<10^{-9} \mathrm{~s}$ and slightly below $10^{-5} \mathrm{~s}$ (that is proton Larmor frequencies going from around $>10^{9} \mathrm{~Hz}$ to $\approx 10^{5} \mathrm{~Hz}$ ), chemical exchanges take place in the time interval $\approx 10^{-5}-10^{-3} \mathrm{~s}$ (which corresponds to proton Larmor frequencies going from around $10^{5} \mathrm{~Hz}$ to around $10^{3} \mathrm{~Hz}$ ), and diffusion occurs on a time scale $>10^{-3} \mathrm{~s}$ (that is proton Larmor frequency $<10^{3} \mathrm{~Hz}$ ). Spanning five orders of magnitude on the time scale reported in Figure 1, fast field-cycling NMR relaxometry can monitor a wide set of molecular motions going from slow tumbling to slow diffusion. When compared to the other NMR techniques, the advantage of FFC NMR relaxometry is its larger sensitivity for the aforementioned molecular motions as a result of the special design of the hardware system [24].

FFC NMR relaxometry versatility makes the technique quite useful in many fields. As an example, it has been applied to monitor food quality [25,26], traceability [27-29], conservation [30], and transformation [31-37]; to evaluate the physical chemical characteristics of systems useful for drug delivery [38]; to design new contrast agents to be used in diagnostic imaging techniques [39-41]; to explore tumor development [42]; to monitor environmental quality [18,43,44], and many other different applications that can be found elsewhere [45,46]. 


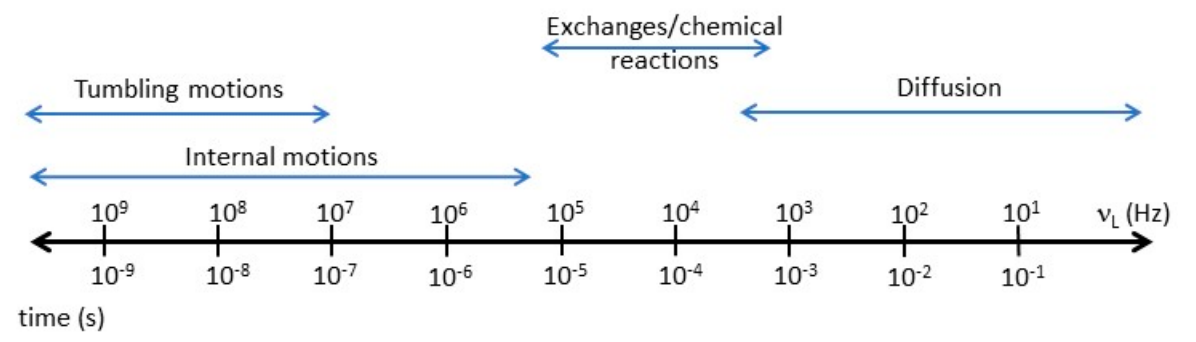

Figure 1. Time scale of molecular motions unveiled by different NMR techniques. The top side of the scale indicates the strength of the applied magnetic field in terms of proton Larmor frequency.

The present review paper is intended to explore the suitability in soil science of FFC NMR relaxometry. Firstly, a general overview of the mechanisms of longitudinal relaxation is provided. Secondly, the basic FFC NMR experiment is described. Then, the mathematical models to interpret FFC NMR relaxometry data are indicated. Finally, the reliability of the technique in soil science is described, thereby also suggesting a molecular mechanism in order to explain how water dynamics in soils can influence movement of nutrients towards plant roots.

\section{The Meaning of the $T_{1}$ Value}

$T_{1}$ (i.e., the longitudinal relaxation time) quantifies the time needed to recover the longitudinal component of the magnetization along the direction of the applied magnetic field (conventionally the $\mathrm{z}$-axis) [10]. Its value depends on the fluctuating local electric/magnetic fields that are generated by either unpaired electrons, or nuclear dipoles, or charged particles interacting with nuclear quadrupole moments for nuclei with spin number $>\frac{1}{2}$ (e.g., $\left.{ }^{14} \mathrm{~N}\right)$, or even anisotropy of the chemical shielding tensor, and finally fluctuating scalar coupling interactions and molecular rotations [10]. Among the aforementioned factors, the molecular motions appear to be very important in affecting the fluctuations of the local electro-magnetic fields [10]. Consequently, the evaluation either of the longitudinal relaxation time or the longitudinal relaxation rate $\left(R_{1}\right)$-which is the inverse of $T_{1}$-can provide valuable information on molecular dynamics.

In soils, the longitudinal relaxation time of water hydrogen nuclei (that is the main component of the soil solution) is influenced by the porous boundaries and the presence of quadrupolar systems [47].

Quadrupolar nuclei are those having quantum spin number $(S)>\frac{1}{2}$. Such nuclei show non-spherically symmetric charge distribution, which is represented by a non-zero quadrupolar momentum $\left(\mu_{Q}\right)$. The latter affects the effective strength of the applied magnetic field $\left(\boldsymbol{B}_{0}\right)$ felt by the investigated nucleus (that is ${ }^{1} \mathrm{H}$ for water in soils), thereby shortening its longitudinal relaxation time value. However, the $\mu_{Q}$ values are not only dependent on the size and the charge of the nucleus, but also on the symmetry of the structure of the molecular system where that nucleus lays. Therefore, it must not be a surprise if some of the nuclei that are of interest for soil scientists reveal the quadrupolar effect despite their nuclear quantum spin number being $\frac{1}{2}$ [47]. In fact, while the quadrupolar effect is null in chemical environments with cubic local symmetry (point groups $T_{d}$ and $O_{h}$ ), most coordination environments in minerals have lower symmetries $[47,48]$.

As stated above, the longitudinal relaxation is also dominated by possible strong relaxation sinks present at the pore surface. These are caused by temporary adsorption of water molecules by means of weak interactions [44]. When water tumbling is reduced due to the interactions with the solid surface, the efficiency of the dipolar ${ }^{1} \mathrm{H}-{ }^{1} \mathrm{H}$ interactions increases. Hence, reduction in the ${ }^{1} \mathrm{H} T_{1}$ value is observed [44]. In particular, the strength of the water-solid surface interactions is influenced by the pore size of the porous system. In fact, the smaller the pore size (such as in clayey soils), the slower the molecular motions due to space restrictions. This leads to the aforementioned more efficient ${ }^{1} \mathrm{H}-{ }^{1} \mathrm{H}$ dipolar interactions and ${ }^{1} \mathrm{H} T_{1}$ reduction. Conversely, as molecular mobility increases because of pore size enlargement (e.g., in silty and sandy systems), the ${ }^{1} \mathrm{H}-{ }^{1} \mathrm{H}$ dipolar interactions weaken and longer longitudinal relaxation times are measured [44]. In other words, shorter $T_{1}$ values can be associated 
with the movement of water into small-sized pores. These are typical features of clay-rich systems such as clay primary particles and small soil aggregates. Longer $T_{1}$ values may be led back to the movement of water in silt, sand particles, and large aggregates. However, because the size and number of particles in soils is heterogeneous, water molecules perceive a wide variety of differently sized pores, which results in broad continuous distribution of longitudinal relaxation times [49]. Water molecules moving inside the smallest pores provide a range of $T_{1}$ values closer to the shortest $T_{1}$ limit. On the other hand, water molecules that move inside the largest pores produce $T_{1}$ values closer to the longest $T_{1}$ limit. All $T_{1}$ values between the two limits are due to water molecules moving inside pores having sizes comprised between the two extremes [49].

\section{The Fast Field-Cycling NMR Experiment and the Evaluation of the $T_{1}$ Value}

\subsection{The Inversion Recovery Sequence and the Basic FFC NMR Experiment}

Figure 2A reports the scheme for the classic $180-\tau-90$ inversion recovery (IR) experiment designed to measure the value of the longitudinal relaxation time. The three periods of preparation, evolution and acquisition are also indicated.

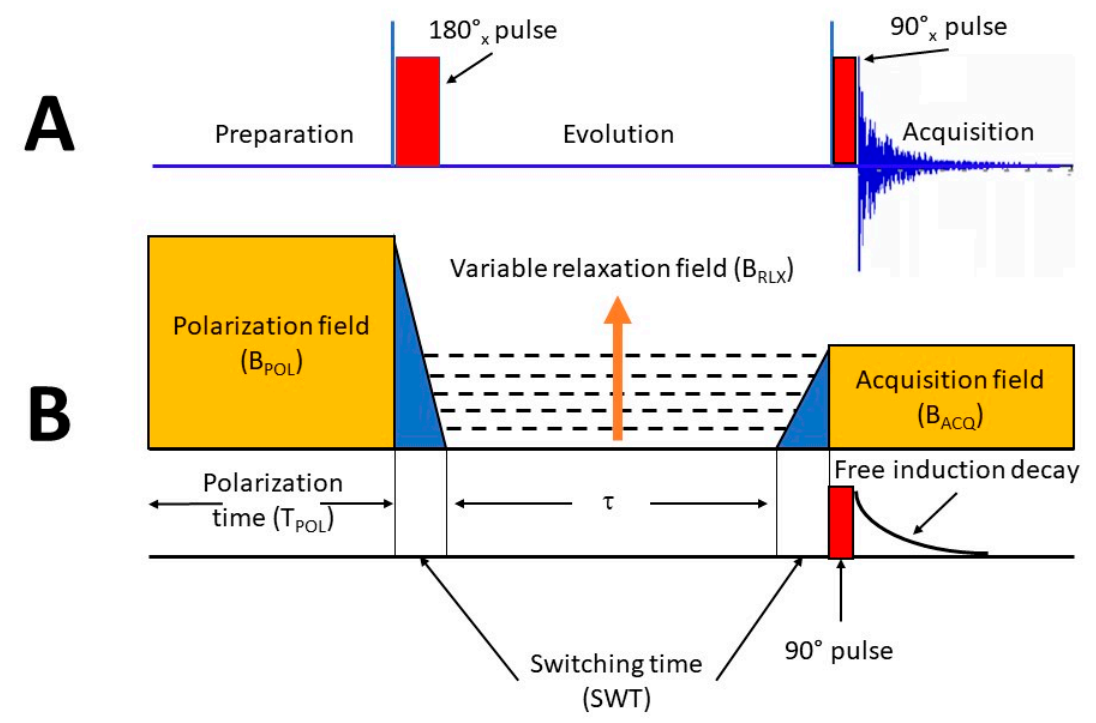

Figure 2. (A). Typical inversion recovery sequence applied in NMR spectroscopy to measure $T_{1}$ values.

(B). Fast field sequence applied to obtain the $T_{1}$ values in relaxometry experiments.

At the end of the preparation period (which is a waiting time needed to let the magnetization completely regain its alignment along the direction of $\boldsymbol{B}_{\mathbf{0}}$ ), an inversion pulse is applied in order to flip the magnetization along -z. Then, the evolution period is set to be varied within a series of progressively increasing time intervals, $\tau$. During each $\tau$, the magnetization evolves towards the equilibrium condition along the direction of the applied magnetic field. Finally, at the end of each evolution time with the duration of $\tau$, a $90^{\circ} \times$ pulse is applied in order to generate the observable and acquire the free induction decay (FID) signal [50].

Signal intensity depends on the $\tau$ values as described in Equation (1), where $I(\tau)$ is the signal intensity at the end of the evolution period with duration $\tau$, and $I_{0}$ is the signal intensity when $\tau=0$ [50].

$$
I(\tau)=I_{0}\left(1-2 e^{-\frac{\tau}{T_{1}}}\right)
$$

The use of any fitting software where $I(\tau)-\mathrm{vs}-\tau$ is reported, allows the achievement of both $I_{0}$ and $T_{1}$. 
The inversion recovery sequence is quite simple to be applied. However, it is designed to be used in high-field NMR spectroscopy and, hence, to retrieve information about fast molecular motions in purified molecules. As a general remark, it must be also mentioned that the acknowledgment of the $T_{1}$ values via the inversion recovery sequence allows one to understand the $3 \mathrm{D}$ conformation of pure systems [50].

When dealing with very complex mixtures (e.g., dissolved organic matter, soils soaked with water solutions, etc.), one cannot apply NMR spectroscopy to recognize the three-dimensional structure of a molecular system. In fact, mixture complexity makes spectroscopy only suitable to gain information on the general chemical nature of the mixture components. In other words, the NMR signals are assigned to general classes of functional moieties such as aromatic groups (resonating in the chemical shift interval 160-110 ppm), carbohydrate units (acquired in the chemical shift interval 110-40 ppm), alkyl systems (resonating in the interval $40-0 \mathrm{ppm}$ ), etc. [1]. Therefore, the application of the inversion recovery sequence to unveil 3D structures and conformations is useless. However, the IR experiment can still be applied to understand the molecular dynamics of the aforementioned classes of compounds. As a matter of fact, the direct relationship between $T_{1}$, temperature, and correlation time $\left(\tau_{C}\right.$, that is, the time needed for a molecule to rotate one rad or to move within a distance corresponding to its length) [51] permits one to understand how strongly the motion of molecular groups is restrained [10].

There are at least two limitations in the use of the inversion recovery sequence to study molecular dynamics of complex mixtures. The first one is the necessity to apply variable temperature experiments in order to obtain information about correlation times, while the second limit is due to the application of static high magnetic fields. Variable temperatures can be detrimental when temperature sensitive organic systems are analyzed. In fact, the latter can decompose, and artifacts can be obtained. Static high magnetic fields needed to acquire high sensitivity spectra (i.e., spectra with a signal-to-noise ratio at least $>10$ ) allow detection of fast molecular motions only (Figure 1). As a consequence, the dynamics of slow motions, such as those occurring on the surface of porous systems, are missed. Therefore, the fast field-cycling sequence reported in Figure 2B must be applied [18]. In fact, it allows the monitoring of the $T_{1}$ values of complex systems in a range of proton Larmor frequencies going from 0.01 up to $40 \mathrm{MHz}$ with a single instrument. In addition, the correlation times can be measured at room temperature or in conditions that are able to prevent thermal decomposition of organic matter. Of course, being a low field technique, all the spectroscopic information is lost.

In the FFC NMR sequence of Figure 2B, the preparation time corresponds to the application (for a fixed period of time also referred to as polarization time, $\left.T_{P O L}\right)$ of a polarization field $\left(\boldsymbol{B}_{P O L}\right)$. Its value can be either non-null or null. In the first case, a pre-polarized (PP) sequence is achieved, while in the second case a non-polarized (NP) sequence is retrieved.

The pre-polarization is needed to generate the magnetization that evolves to reach a new equilibrium condition (evolution period) under the action of a relaxation field $\left(\boldsymbol{B}_{R L X}\right)$ applied for a variable period $\tau$. The acquisition time starts at the end of the evolution: the magnetic field intensity is switched to a new value (indicated as $\boldsymbol{B}_{A C Q}$ ), while a $90^{\circ}$ pulse is applied to generate the observable magnetization, and the FID is finally acquired.

The use of the PP sequence is recommended whenever the intensity of the relaxation field is very low, therefore enhancement in sensitivity is needed. The crossover field between the PP and the NP sequences might be fixed empirically at $\omega_{R L X}=\frac{\omega_{P O L}}{2}$, where $\omega_{R L X}$ and $\omega_{P O L}$ are the $\boldsymbol{B}_{R L X}$ and the $B_{P O L}$ proton Larmor frequencies expressed in $\mathrm{MHz}$, respectively.

In Figure 2B, a switching time (SWT) is also indicated, i.e., the time needed to switch between different magnetic field intensity values. SWT is usually set at ca. $3 \mathrm{~ms}$. Shorter SWT values can be only applied providing that peculiar electronic precautions are adopted [52].

\subsection{How to Obtain the $T_{1}$ Value from the FFC NMR Experiment}

Figure 3 shows a typical dataset for the decay and recovery curves obtained by the PP and NP sequences, respectively. The full lines represent the data fitting by using the bi-exponential form 
of Equation (2) for the PP sequence and Equation (3) for the NP sequence. The dataset depicted in Figure 3 has been acquired by saturating a quartz sand with Milli-Q grade water (see Appendix A for the details of the experiment).

$$
\begin{gathered}
I(\tau)=a+\sum_{i=1}^{N} b_{i} e^{-\frac{\tau}{T_{1 i}}} \\
I(\tau)=a+\sum_{i=1}^{N} b_{i}\left(1-e^{-\frac{\tau}{T_{1 i}}}\right)
\end{gathered}
$$

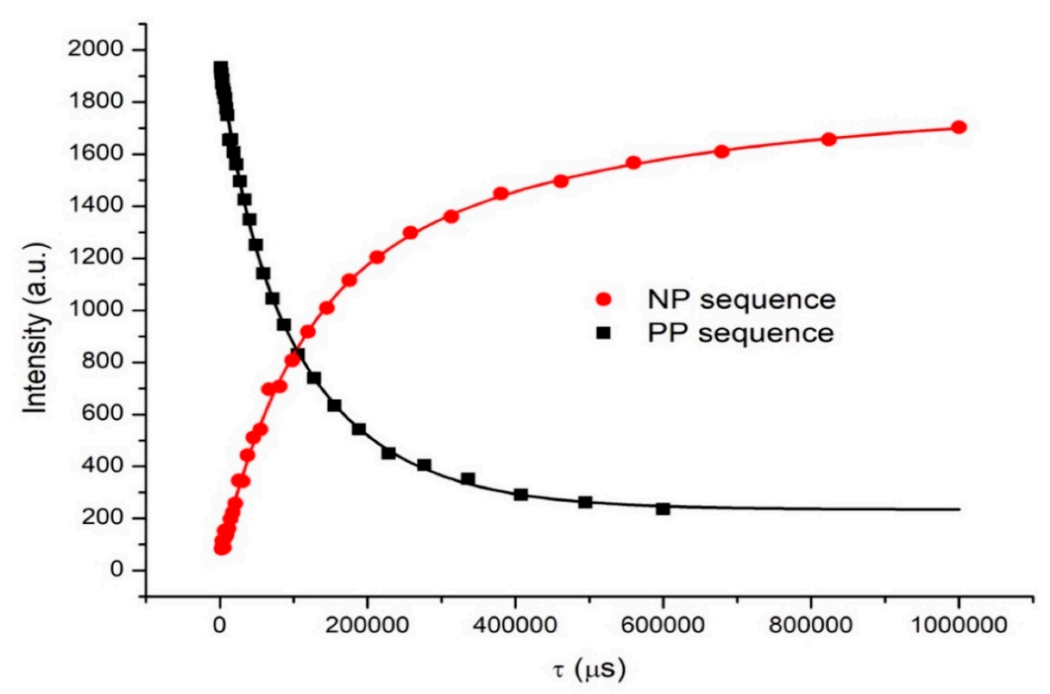

Figure 3. Decay and recovery curves obtained by applying the pre-polarized (PP) and non-polarized (NP) sequences, respectively. The dots are the data points collected by analyzing a sample of quartz sand ( $1 \mathrm{~g}$ ) filled with Milli-Q grade water ( $3 \mathrm{~mL})$. The PP sequence was applied at a relaxation field $\left(\boldsymbol{B}_{R L X}\right)$ proton Larmor frequency of $0.1 \mathrm{MHz}$, while the $B_{R L X}$ proton Larmor frequency for the NP sequence was $30 \mathrm{MHz}$. The full lines are the fitting curves obtained by applying the biexponential form of Equations (2) and (3) for the PP and NP sequence, respectively (unpublished results).

In both Equations (2) and (3), $I(\tau)$ is the signal intensity at the selected $\tau$ value, $a$ is the offset and $b_{i}$ is the magnetization intensity at the Boltzmann equilibrium of the $i$-th component of the molecular motion at each fixed $\boldsymbol{B}_{R L X}$ intensity [18].

The limit of Equations (2) and (3) lies in the need to make assumptions on the number of exponential components to be used for data fitting. From a mathematical point of view, the larger the number of exponential components, the better the quality of the fitting, at least when a hyper-corrected model is used. Therefore, any assumption made on the number of components to be considered in the aforementioned equations is arbitrary, and, hence, questionable, when the system under consideration is unknown and complex (e.g., the case of soil systems). In order to overcome the aforementioned limits, the stretched Equations (4) and (5), for the pre-polarized and non-polarized sequence, respectively, can be applied [18].

$$
\begin{gathered}
I(\tau)=a+b \times e^{-\left(\frac{\tau}{T_{1}}\right)^{k}} \\
I(\tau)=a+b \times\left(1-e^{-\left(\frac{\tau}{T_{1}}\right)^{k}}\right)
\end{gathered}
$$

In Equations (4) and (5), $a$ and $b$ have the same meaning as in Equations (2) and (3), and $k$ is a heterogeneity parameter that is related to the stretching of the decay/recovery processes. The use of Equations (4) and (5) offers the advantage to deal with a large variety of different behaviors within a 
single model, thereby avoiding arbitrary assumptions about the number of exponentials to be applied in modelling the relaxometric results.

\section{From Time Domain to Time Domain}

The mathematical models given in Equations (2) and (3) can be considered as a discrete representation of the $T_{1}$ distribution of a molecular system. They provide valuable information only when the longitudinal relaxation times in a complex system are very different to each other. As an example, with the assumption of a biexponential decay/recovery for the water in equilibrium with the surface of a quadrupolar-less-nuclei quartz sand used as porous system model (Figure 3 ), the $T_{1}$ values reported in Table 1 are obtained.

Table 1. Longitudinal relaxation times for the quartz sand sample added with Milli-Q grade water as described in the caption of Figure 3. $\omega_{L}$ is the proton Larmor frequency of the applied $\boldsymbol{B}_{R L X}$.

\begin{tabular}{ccc}
\hline$\omega_{L} \mathbf{( M H z )}$ & $\boldsymbol{T}_{1}^{\text {slow }} \mathbf{m s}$ & $\mathbf{T}_{1}^{\text {fast }} \mathbf{m s}$ \\
\hline 0.1 & 129 & 34 \\
30 & 445 & 96 \\
\hline
\end{tabular}

Here, $T_{1}^{f a s t}$ may refer to the relaxation time of water molecules in the closest proximity of the solid surface, while $T_{1}^{\text {slow }}$ may be the relaxation time of the water molecules flowing farther from the surface (Figure 4A). However, according to the mechanisms outlined in Section 2, one can also stand that $T_{1}^{\text {fast }}$ is due to water molecules moving in pores smaller than those where water molecules generating $T_{1}^{\text {slow }}$ lay (Figure 4B). Actually, without the aid of any additional information, there is no reason to place trust in one of the different aforementioned hypotheses. It is also possible that a combination of all the aforesaid dynamics may occur (Figure 4C). However, this latter information has not been accounted for in the biexponential assumption used to apply Equations (2) and (3).

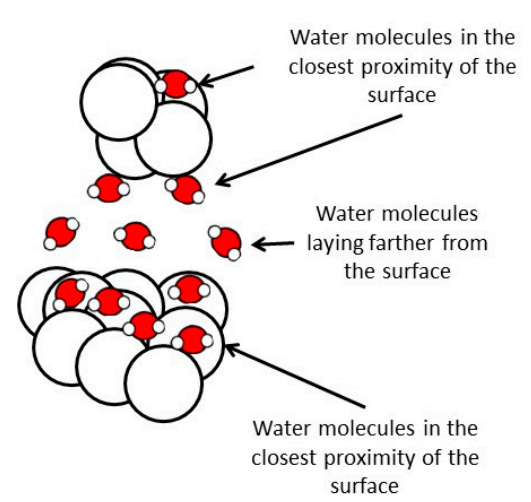

A

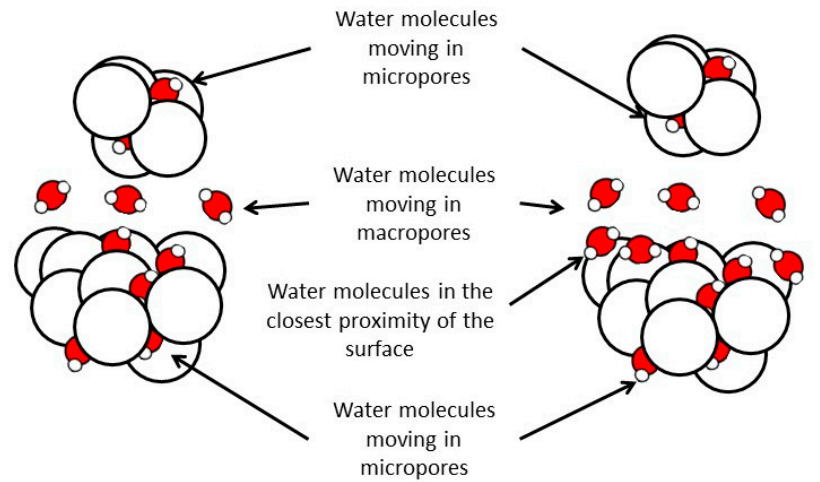

B

Figure 4. Different dynamics of water molecules in the quadrupolarless-nuclei quartz sand used as a porous system model (white circles). The biexponential assumption used to apply Equations (2) and (3) is valid only for $\mathbf{A}$, and $\mathbf{B}$. In case $\mathbf{C}$, a three-exponential model should be applied.

Due to the very good fitting $\left(\mathrm{R}^{2}>0.99\right)$ provided by the biexponential assumption (Figure 3$)$, there is no mathematical reason to apply for the three-exponential form of Equations (2) and (3) in order to introduce a hypothetical complexity in the dynamic behavior of water molecules in equilibrium with the solid surface of the quartz sand. Certainly, the approximation given by Equations (4) and (5) does not help in solving the complexity of water dynamics in quartz sand. In fact, those equations 
provide only one average $T_{1}$ value, and a $k \neq 1$. It is not yet clear what the relationship between the heterogeneity parameter and the number of the different $T_{1}$ components associated with water dynamics is.

When the various components of the molecular dynamics in multi-phase frames are described by longitudinal relaxation rates (the values of which are very close), their $T_{1}$ distributions can be more suitably obtained by applying an inverse Laplace transform. It can be expressed as in Equation (6) when pre-polarized experiments are performed and in the form of Equation (7) when the non-polarized experiments are carried out [18].

$$
\begin{gathered}
I(\tau)=\int_{T_{1}^{\min }}^{T_{1}^{\max }} D\left(T_{1}\right) e^{-\left(\frac{\tau}{T_{1}}\right)} d\left(T_{1}\right)+\sigma \\
I(\tau)=\int_{T_{1}^{\min }}^{T_{1}^{\max }} D\left(T_{1}\right)\left(1-e^{-\left(\frac{\tau}{T_{1}}\right)}\right) d\left(T_{1}\right)+\sigma
\end{gathered}
$$

In Equations (6) and (7), $T_{1}^{\min }$ and $T_{1}^{\max }$ are the suitable limits within which all the $T_{1}$ values range; $D\left(T_{1}\right)$ is the relevant distribution function that must be determined by solving either Equation (6) or Equation (7); $\sigma$ is a parameter accounting for a suitable unknown noise component. The most likely distribution of $T_{1}$ values may be obtained when some constraints, such as variance of the experimental data or smoothness of the solution, are taken into account.

Two algorithms have been developed to switch from $I(\tau)$ to $D\left(T_{1}\right)$. These are the continuous distribution, also referred to as CONTIN, [53,54], and the uniform penalty regularization, also referred to as UPEN [13-15]. The two algorithms differ in the smoothing procedure used. Nevertheless, it worth underlying that the two algorithms provide de facto similar $T_{1}$ distributions, also referred to as relaxograms (Figure 5), regardless of the procedure used to obtain the most probable distribution of relaxation times.

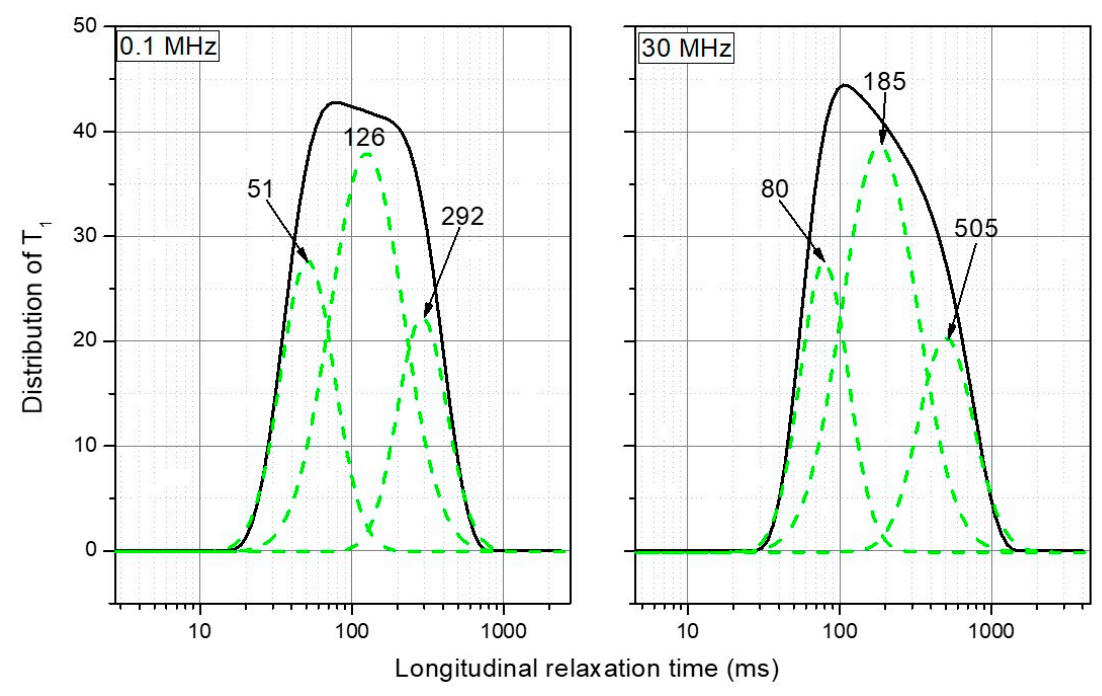

Figure 5. Relaxograms obtained by the uniform penalty regularization (UPEN) algorithm applied on the decay and recovery curves reported in Figure 3. The dashed green lines represent the deconvolution curves of the two relaxograms (unpublished results).

Figure 5 shows the relaxogram obtained by applying the UPEN algorithm to the data points reported in Figure 3. It is clear, now, that water dynamics in the quartz sand is more complex than the simple data interpretation based on the biexponential form of Equations (2) and (3). In fact, the inspection of Figure 5 reveals that three different $T_{1}$ components are distinguishable. They are centered at around 51, 126, and $292 \mathrm{~ms}$ in the relaxogram acquired at the ${ }^{1} \mathrm{H}$ Larmor frequency of $0.1 \mathrm{MHz}$, 
while they are displaced at around 80, 185 and $505 \mathrm{~ms}$ in the relaxogram obtained by using the proton Larmor frequency of $30 \mathrm{MHz}$. Both relaxograms in Figure 5 do not show any band at around $2.5 \mathrm{~s}$, which is the typical longitudinal relaxation time of free water [38]. This finding can only mean that all the water is trapped inside the quartz sand. It is, then, conceivable that water can be subjected to a horizontal surface diffusion (Figure 6A); a diffusion in the spaces among quartz sand particles, which can be indicated as interparticle diffusion (Figure 6B); and a diffusion inside the internal pores of each sand particle, also referred to as intraparticle diffusion (Figure 6C) [49].

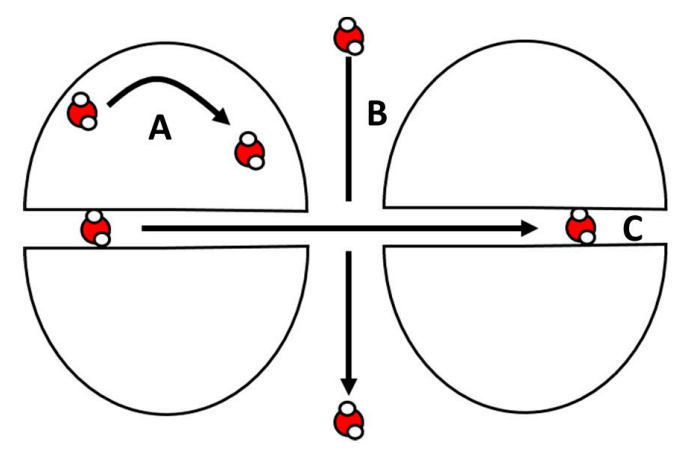

Figure 6. Representation of the three different motions of $\mathrm{H}_{2} \mathrm{O}$ molecules in quartz sand as inferred by the results of the relaxograms reported in Figure 5. A. Horizontal surface diffusion. B. Interparticle diffusion. C. Intraparticle diffusion.

\section{The Nuclear Magnetic Resonance Dispersion (NMRD) Profile and Its Modeling}

The $T_{1}$ values obtained via Equations (2) to (5) can be plotted versus $\boldsymbol{B}_{R L X}$ proton Larmor frequency in order to obtain an NMRD profile. Its typical shape is a sigmoidal curve (Figure 7), which is mathematically described by Equation (8) [20].

$$
R_{1}=\frac{1}{T_{1}}=\frac{2 \tau_{C}}{1+\left(\omega_{L} \tau_{C}\right)^{2}}
$$

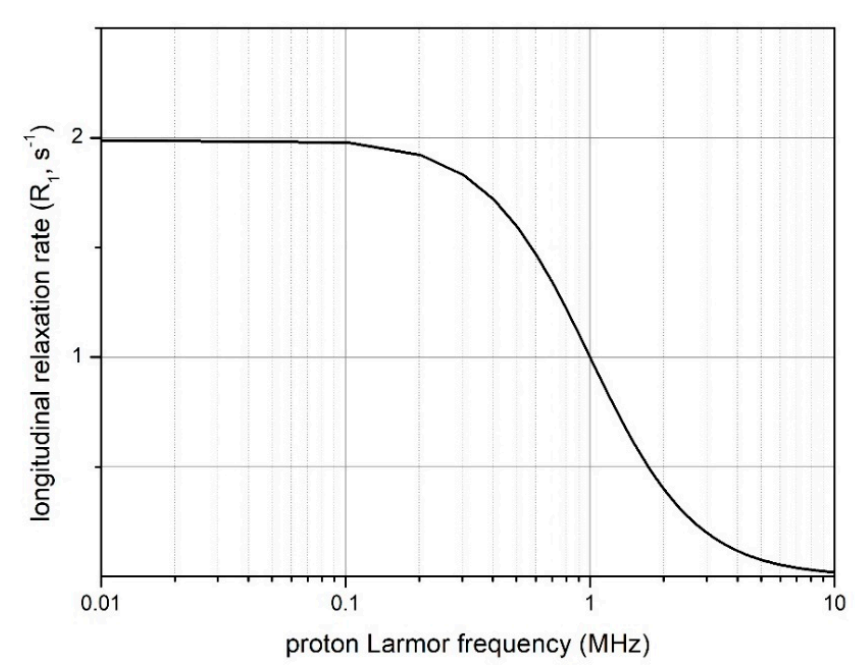

Figure 7. Typical sigmoidal shape of a nuclear magnetic resonance dispersion (NMRD) profile.

In Equation (8), $R_{1}$ is the longitudinal relaxation rate $\left(R_{1}=1 / T_{1}\right)$ which represents the distribution of the motion frequencies in a molecular system; $\omega_{L}$ is the $\boldsymbol{B}_{R L X}$ intensity given as proton Larmor frequency; and $\tau_{c}$ is the relevant correlation time [10]. The latter, indeed, describes the random molecular motions of molecular systems either in solution or in porous media. In particular, the larger 
the $\tau_{c}$ value, the slower the molecular motions, thereby accounting for the existence of restraints in the motional degrees of freedom. Conversely, as a molecule encompasses faster motions in larger spaces, shorter $T_{1}$ values are expected [18] (see also Appendix B for further mathematical details).

Luchinat and Parigi [55] reported that protein dilute aqueous solutions can be investigated by using Equation (9), also referred to as the Bloembergen-Purcell-Pound (BPP) model. The latter has been obtained for aqueous systems where bulk water is dominant [51]. Therefore, protein dynamics can be indirectly revealed by using water molecules as target for the relaxometric investigations. As will be clarified below, Equation (9) as well as its modifications [55] can also be applied to recognize the properties of environmentally relevant porous systems via the indirect observations made on water molecules in equilibrium with the solid surfaces $[49,56]$.

$$
R_{1}=\frac{1}{T_{1}}=\alpha+\beta\left[\frac{0.2 \tau_{\mathcal{C}}}{1+\left(\omega_{L} \tau_{C}\right)^{2}}+\frac{0.8 \tau_{\mathcal{C}}}{1+\left(4 \omega_{L} \tau_{C}\right)^{2}}\right]
$$

In Equation (9), all the terms in the squared brackets have the same meaning as in Equation (8), while $\alpha$ is the high-field relaxation rate and $\beta$ is a parameter that relates to the dipolar interactions. The latter contains the Planck constant, the proton quantum-spin number, the gyromagnetic ratio, and the electron-nuclear hyperfine coupling constant (which in turn accounts for the interactions between resonant protons and unpaired electrons). The higher the $\beta$ value, the stronger the dipolar interactions responsible for the relaxation.

It is well recognized that neither Equation (8) nor Equation (9) satisfactorily fit the experimental data points when a stretched dispersion is retrieved. The stretching depends on how complex the re-orientational dynamics within the molecular systems are, as well as on the heterogeneous distribution of intermolecular dipole couplings and proton exchange rates [18]. An example of stretched dispersion is given in Figure 8, where the NMRD profile of one of the water saturated soils analyzed in Reference [57] is reported.

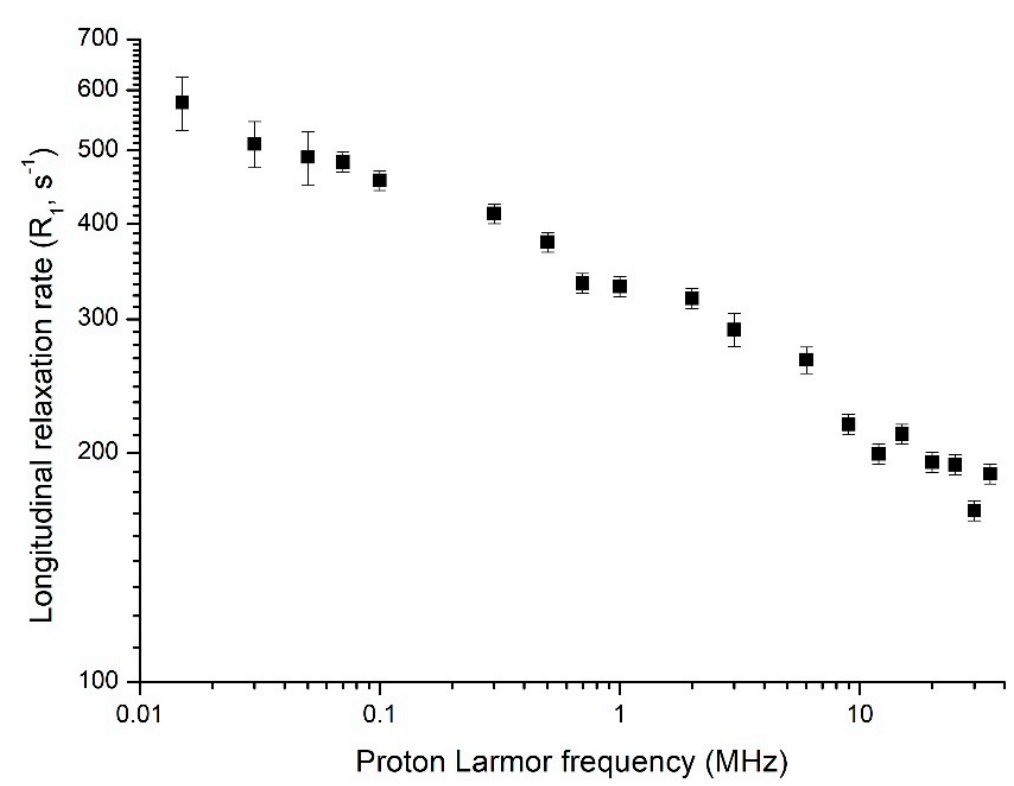

Figure 8. NMRD profile of one of the water-saturated soils analyzed in [57] (unpublished data). Owing to the complexity of the dynamics of $\mathrm{H}_{2} \mathrm{O}$ molecules on the porous surface, the shape of the dispersion is not sigmoidal, such as in Figure 7, but stretched. 
In order to account for the NMRD stretching, Halle and coworkers [58] developed the free model analysis given in Equation (10):

$$
R_{1}=\sum_{i=1}^{N} \frac{C_{i} \tau_{C}^{i}}{1+\left(\omega_{L} \tau_{C}^{i}\right)^{2}}
$$

where the $i$ index refers to the different components of the motion, $\tau_{C}^{i}$ is the correlation time of the $i$-th component, and $C_{i}$ is a fitting parameter. The sum of the $C_{i}$ values constitutes the mean square fluctuation bearing the information on the equilibrium structure of the system and is not dependent on its dynamics.

To limit the number of components to be used in the free model analysis, Halle et al. [58] suggested the application of the F-test. In other words, 'any fit obtained by using $N$ Lorentzian terms to $M$ data points $J\left(\omega_{i}\right)$, with errors $\sigma_{\mathrm{I}}$, provides a $\chi^{2}(N)$ value. The latter must be compared with the $\chi^{2}(N+1)$ value obtained by applying $N+1$ Lorentzians. If the fit improves, the ratio $F_{(N, N+1)}=$ $\chi^{2}(N) / \chi^{2}(N+1)$ increases [i.e., $\chi^{2}(N+1)<\chi^{2}(N)$ ]. The procedure must be iterated until $F_{(N+m-1, N+m)}$ $>F_{(N+m, N+m+1)}$, where $m$ is an integer and $\geq 0$. When the latter condition is satisfied, the acceptable number of Lorentzians to be applied is $N+m^{\prime}$ [58].

It is noteworthy that the free model analysis is only a convenient mathematical approach to fit the experimental data such as those shown in Figure 8. The set of $\left\{C_{i}, \tau_{C}^{i}\right\}$ parameters from Equation (10) have no physical meaning, unless independent information suggests that the investigated system can be modelled by a fixed number of Lorentzians. In the latter case, a direct physical interpretation of the parameters can be attempted. Nevertheless, according to Halle et al. [58], the aforementioned parameters can be used to calculate a weight-averaged correlation time as in relation (11):

$$
\left\langle\tau_{C}\right\rangle=\frac{\sum_{i=1}^{N} C_{i} \tau_{C}^{i}}{\sum_{i=1}^{N} C_{i}}
$$

The combination between the free model analysis given in Equation (10) and the BPP model reported in Equation (9), provides the BPP free model analysis as in Equation (12) [49,55,56].

$$
R_{1}=\alpha+\beta\left[0.2 \sum_{i=1}^{N} \frac{C_{i} \tau_{C}^{i}}{1+\left(\omega_{L} \tau_{C}^{i}\right)^{2}}+0.8 \sum_{i=1}^{N} \frac{C_{i} \tau_{C}^{i}}{1+\left(\omega_{L} \tau_{C}^{i}\right)^{2}}\right]
$$

All the parameters in Equation (12) have been already defined. The set of $\left\{C_{i}, \tau_{C}^{i}\right\}$ parameters from the BPP free model analysis are used to obtain the weight-average correlation time given in relationship (11).

Instead of the aforementioned models, the NMRD profiles can be analyzed by applying a very elegant model provided by Korb and coworkers [59]. This model was designed to interpret NMRD data points acquired for systems presenting paramagnetic impurities (Equation (13)).

$$
R_{1}\left(\omega_{I}, \omega_{S}\right)=R_{0}+K \tau_{m}\left[3 \ln \left(\frac{1+\omega_{I}^{2} \tau_{m}^{2}}{\left(\frac{\tau_{m}}{\tau_{s}}\right)^{2}+\omega_{I}^{2} \tau_{m}^{2}}\right)+7 \ln \left(\frac{1+\omega_{s}^{2} \tau_{m}^{2}}{\left(\frac{\tau_{m}}{\tau_{s}}\right)^{2}+\omega_{s}^{2} \tau_{m}^{2}}\right)\right]
$$

where $\omega_{I}$ is the intensity of $\boldsymbol{B}_{R L X}$ expressed as ${ }^{1} \mathrm{H}$ Larmor frequency; $\omega_{S}=659 \omega_{I}$ is the Larmor frequency of the unpaired electron in the paramagnetic species; $R_{0}$ is the sum of the water bulk relaxation time of the order of $2.5 \mathrm{~s}$ and the frequency independent water-bound contribution, which depends on the amount of water-binding sites. The term in squared brackets in Equation (13) is 
the surface contribution relevant to the surface diffusion of $\mathrm{H}_{2} \mathrm{O}$ molecules near the paramagnetic relaxation source $\left(\mathrm{Fe}^{3+}\right.$, for instance). $K$ is provided by the relationship:

$$
K=\frac{\pi}{30 \delta_{\text {water }}^{3}} \sigma_{S} \rho_{\text {water }} S_{P, N M R}\left(\gamma_{I} \gamma_{S} \eta\right)^{2} S_{S}\left(S_{S}+1\right)
$$

where $\delta_{\text {water }}=0.3 \mathrm{~nm}$ is the width of a monomolecular water layer; $\sigma_{S}$ is the density of the paramagnetic ions at the pore surface (i.e., sources of relaxation expressed in a number of paramagnetic spins per $\mathrm{cm}^{2}$ ), $\rho_{\text {water }}=1 \mathrm{~g} \mathrm{~cm}^{-3}$ is water density; $S_{P, N M R}$ (given in $\mathrm{m}^{2} \mathrm{~g}^{-1}$ ) is the NMR-specific surface area calculated as $S_{P} \times F$ (where $S_{P}$ is the surface area achieved by the Brunauer-Emmet-Teller (BET) analysis, while $F<1$ is the solid-to-liquid ratio); $\gamma_{I}$ and $\gamma_{S}=659 \gamma_{I}$ are the proton and electron gyromagnetic ratios, respectively (for the most abundant paramagnetic species). Finally, $S_{S}$ is the spin quantum number of the paramagnetic species. $\tau_{m}$ is the surface diffusion correlation time, while $\tau_{s}$ is indicated as surface residence time. The former represents the "hopping" time of water among surficial binding sites, while the latter $\left(\tau_{s}\right)$ is the time of residence of water on the surface of the porous medium [18]. The $\frac{\tau_{s}}{\tau_{m}}$ ratio is referred to as NMR surface wettability $[60,61]$.

\section{How to Choose the Right Model to Correctly Interpret NMRD Profiles in Soil Science}

In the previous paragraph, several mathematical models to fit the NMRD profiles have been provided. How should one choose the best one for a given set of experimental data dealing with soils and soil related systems? Unfortunately, there is not a general rule. In order to apply any of them, either the congruence between the results coming out from the models and the general properties of the porous system under investigation must be accounted for or, more simply, when not additional information is available, one choses the model which best fits the experimental data.

\subsection{The Application of the BPP Model: The Quadrupolar-Less Nuclei Quartz Sand}

Let us consider, for instance, a sample containing no quadrupolar nuclei such as quartz sand, which has been used as a sample model for the application of Equations (2), (3), (6), and (7). As reported above, a three-exponential behavior appeared to explain the decay/recovery curves acquired at different $\boldsymbol{B}_{\boldsymbol{R} L \boldsymbol{X}}$ intensities. For this reason, the three NMRD dispersion curves reported in Figure 9 have been obtained.

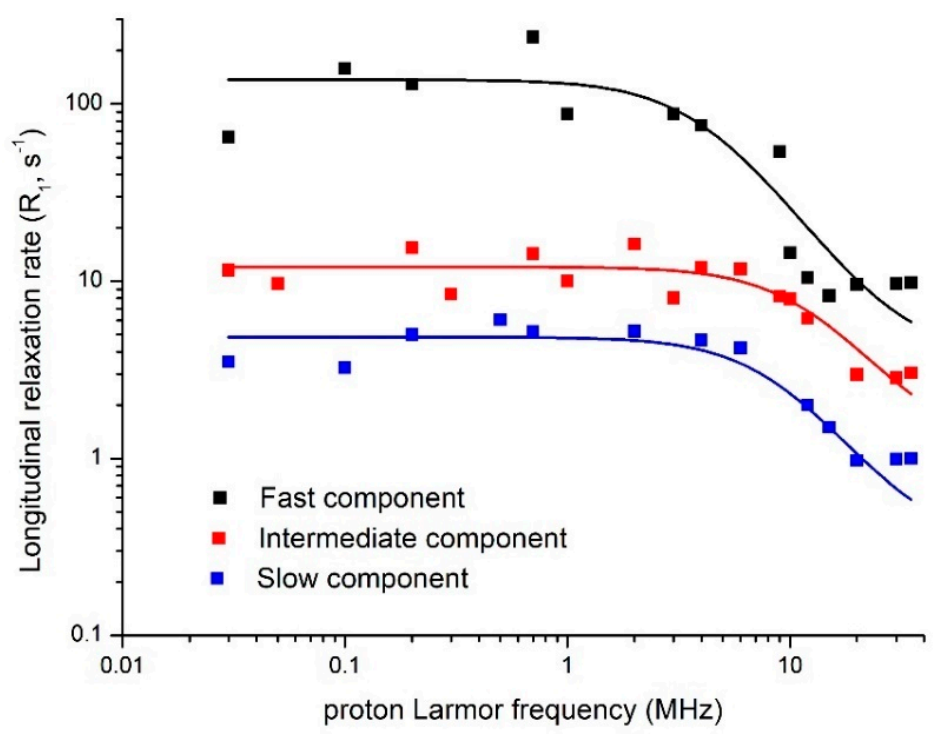

Figure 9. NMRD dispersion profiles of the three motion components of Milli-Q grade water in equilibrium with the quartz sand discussed in the text. The full lines are the fitting curves obtained by the Bloembergen-Purcell-Pound (BPP) model given in Equation (9). 
Visual inspection of Figure 9 allows one to differentiate among a fast component (black data points), an intermediate component (red data points), and a slow component (blue data points) of the water molecular motion. The terms "fast", "intermediate", and "slow" refer to the values of the longitudinal relaxation rates in the entire range of ${ }^{1} \mathrm{H}$ Larmor frequencies which was accounted for. In fact, the fast component revealed the fastest $R_{1}$ values, the slow component showed the slowest $R_{1}$ values, while the $R_{1}$ values for the intermediate component fell all between those measured for the other two components. The three NMRD profiles can be assigned to water molecules subjected to intraparticle diffusion (fast component), to water systems subjected to horizontal diffusion (intermediate component), and to water molecules subjected to interparticle diffusion (slow component) (Figure 6). According to this qualitative evaluation and to the meaning of the $T_{1}$ ( or $R_{1}$ ) values reported in Section 2, one may expect that the correlation times obtainable by the models listed in Section 5, must follow the order: $\tau_{C}^{\text {fast }}>\tau_{C}^{\text {intermediate }}>\tau_{C}^{\text {slow }}$.

Among the different NMRD models, the only one providing the expected results was the BPP model depicted in Equation (9).

Figure 10 reports all the parameters accounted for in Equation (9). The values of the parameter $\alpha$, representing the high-field relaxation rate, follow the relative position of the three profiles in Figure 9. Therefore, $\alpha_{\text {fast }}>\alpha_{\text {intermediate }}>\alpha_{\text {slow }}$.

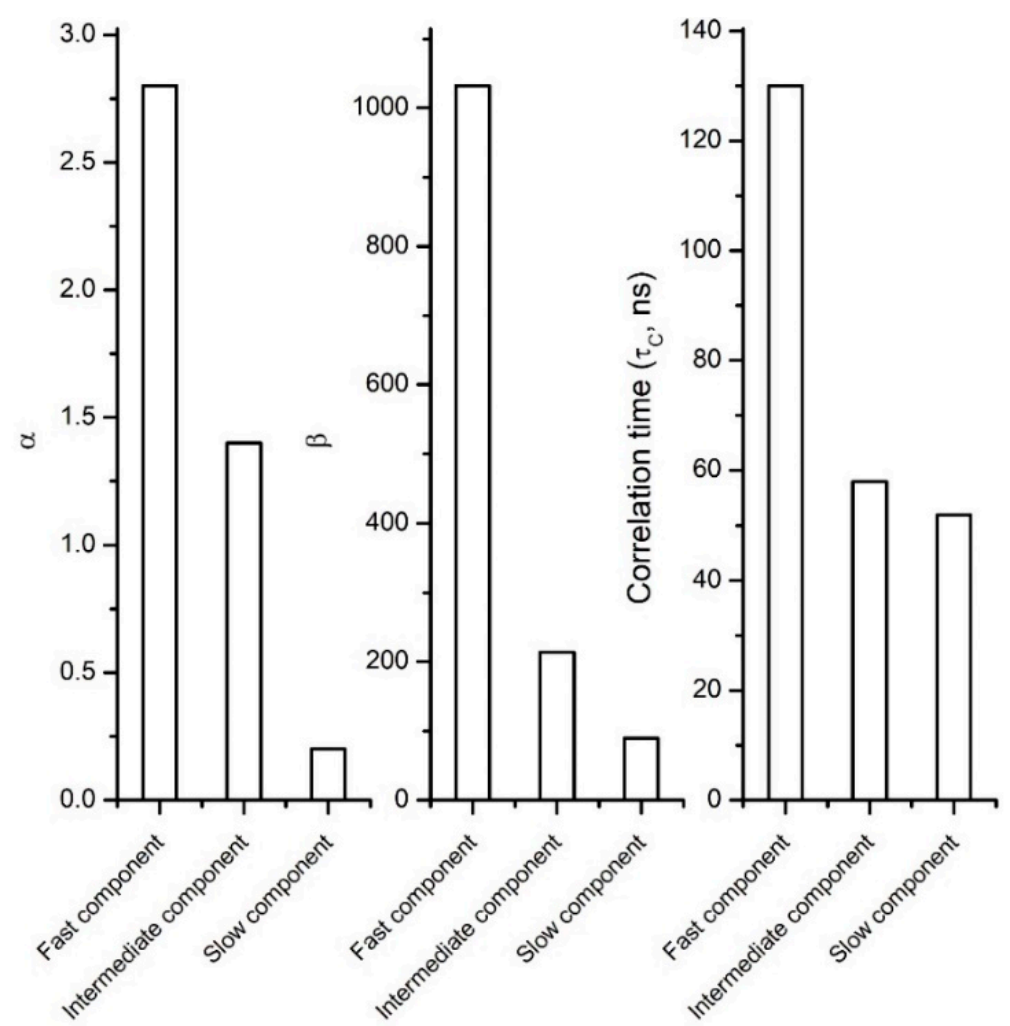

Figure 10. Values of $\alpha, \beta$, and $\tau_{C}$ for the three components of the water motion in quartz sand. These parameters were obtained by fitting the NMRD profiles in Figure 9 by the BPP model given in Equation (9).

The parameter $\beta$ is an indication of the strength of the dipolar interactions occurring between water molecules and the surface of the quartz sand. As reported above, the stronger the dipolar interactions, the shorter is the $T_{1}$ and the faster results the $R_{1}$. For this reason, as expected by the relative position of the three NMRD profiles, the $\beta$ values follow the order $\beta_{\text {fast }}>\beta_{\text {intermediate }}>\beta_{\text {slow }}$.

Finally, the correlation times are in the order: $\tau_{C}^{\text {fast }}>\tau_{C}^{\text {intermediate }}>\tau_{C}^{\text {slow }}$, which confirms the expectations reported above. 


\subsection{When the Free Model Analysis is the Best Choice. Two Case Studies: Soil and Biochar}

The quartz sand discussed above is a very simple system. When dealing with more complex materials, such as soils, the simple BPP model reported in Equation (9) may not be applied. As an example, Laudicina et al. [62] studied the effects of afforestation with four unmixed plant species (Eucalyptus camaldulensis Dehnh., E. occidentalis Endl., Pinus halepensis Mill., and Cupressus sempervirens) on the soil-water interactions in a semiarid Mediterranean region by applying, among the others, fast field-cycling NMR relaxometry. The six-parameter $\left(c_{1}, c_{2}, c_{3}, \tau_{1}, \tau_{2}, \tau_{3}\right)$ free model analysis (that is, Equations (10) and (11)) appeared to provide the best fist for the experimental data. The authors found that the soils under the different plant species may trap water in clay-, loam-, and sand-type pores. In particular, the longest correlation time describes the re-orientational behavior of water confined in clay-type pores, the intermediate value refers to water restricted in loam-type pores, and the shortest correlation time is due to water freely moving in sand-type pores (Figure 11).

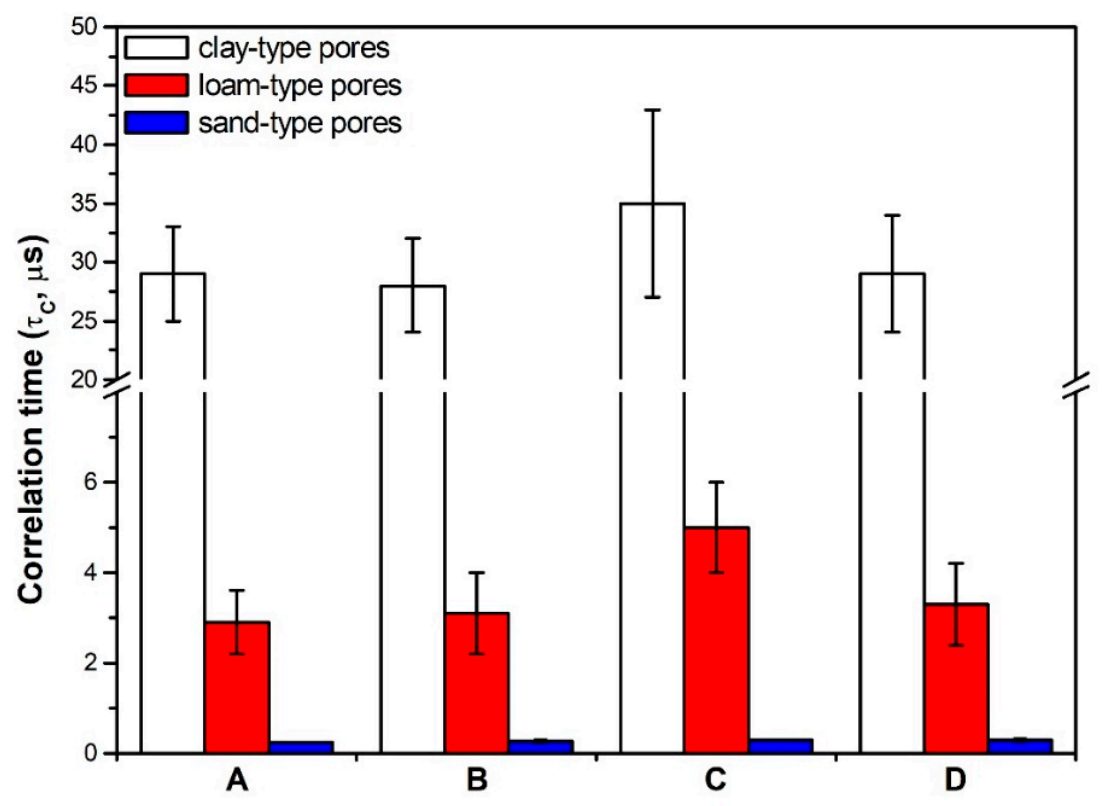

Figure 11. Correlation times obtained by applying a six-parameter free model analysis (Equations (10) and (11)) on the NMRD profiles for soils under A. Eucalyptus camaldulensis Dehnh., B. E. occidentalis Endl., C. Pinus halepensis Mill., and D. Cupressus sempervirens. The longest $\tau_{C}$ value is due to water moving in clay-type pores. The shortest $\tau_{C}$ value is related to water moving in sand-type pores. The intermediate $\tau_{C}$ value is attributable to water moving in loam-type pores. The histogram has been built by using the data from Reference [62].

The free model analysis was also applied in Conte et al. [63] to unveil the nature of the water-biochar interactions. Biochar is a carbonaceous material used to improve soil quality via mechanisms which are still to be clarified [64-67]. In the aforementioned study, NMRD profiles of a water saturated biochar were acquired at different temperatures. The evaluation of the $\tau_{C}$ temperature dependence suggested that water molecules can be hooked to the biochar surface via different types of interactions. On one hand, the electron-rich oxygen atom in water may interact with the electron-poor metals displaced on the biochar surface. On the other hand, the water electron-deficient hydrogen atoms can interact with the electron-rich aromatic moieties of the biochar backbone. Finally, water may also form H-bonds with the functional groups usually present on the biochar surface [68]. These interactions may justify the exceptionally large biochar affinity for nitrate, phosphate and many other plant nutrients $[66,67,69]$, as well as its role in improving soil structure when it is applied as an amendment [70,71], thereby allowing soil fertility enhancement [65]. In fact, water may act as a "glue" layer between biochar and 
soil components. As a consequence, improvement in soil structure can be achieved. The same "glue" layer may also permit the adhesion of anions and cations on the soil/biochar surface [23]. Therefore, gradual and constant nutrient supply to plant roots can be obtained.

\subsection{The Combination between the BPP Model and the Free Model Analysis: The Saltmasrh Sediment Case Study}

The models discussed hereinabove were not appliable to evaluate the characteristics of sediments sampled in a saltmarsh located nearby Trapani (Sicily, Italy) [56]. In this case, the BPP free model analysis given in Equation (12) provided not only the best fit, but also the best numerical results explaining the number of complementary information available on the sediment samples. Indeed, 'FFC-NMR relaxometry data highlight[ed] that water dynamic properties are linked to the sedimentological features of the saltmarsh sediments as well as with metal analyses and benthic foraminiferal density evaluation' [56]. As matter of fact, it was possible to 'subdivide the [sampled sedimentary core] into three time intervals, each characterized by particular biological and geochemical data. In particular, [... ] the lower part of the studied core corresponds to the interval before the inundation occurred on 1965. During this period, sediments were characterized by low anthropogenic pollution, and the studied area was utilized for the production of halite. The saline pans were abandoned between 1965 and 1990, and agricultural production was intensified. Because of this, runoff increased the deposition of inorganic and organic pollutants into ponds. Level of metals decreased, and benthic foraminiferal density improved after the institution of the natural reserve and with the restarting of the salt production. This latter has permitted to connect again the ponds with the sea' [56].

\subsection{NMRD Evaluation by the Wettability Model: Application to Biochar}

The model obtained by Korb coworkers [59] (Equation (13)) can be applied only under the hypothesis that all the parameters reported in relation (14) are known. This model has been designed for the investigations of cement-based materials, plaster pastes and petroleum fluids [61]. However, recently it was also used in a paper by Bubici et al. [60] where biochar water NMR wettability has been investigated.

Water wettability in biochars is a very important parameter to be acquired when the aforementioned carbonaceous material is applied to soils. In fact, it is well recognized that the presence of unsuitable type of biochar or applied amount (due to either uncontrolled forest fires or deliberate application for improvement of soil quality) may cause soil repellency in such a way that affects the ability of soil in absorbing water, inhibiting microbial activity, altering filter, as well as storage, buffer, and transformation functions of the soils [72-74]. It is worth highlighting that up to now the only direct macroscopic way to measure wettability of a porous systems is via the evaluation of contact angles [75,76], although a new predictive, but yet to be confirmed, model recently appeared [77].

Contact angle (CA) is the angle between the intersection of the liquid-solid and the liquid-vapor interfaces. It can be geometrically evaluated by considering in the droplet profile the line tangent to the contact point along the liquid-vapor interface (Figure 12A,B). The technique is based on the surface tension of the liquid. Surface molecules in a liquid do not have neighboring molecules in all directions to provide a balanced net force. By contrast, they are pulled inward by the neighboring molecules, thereby creating an internal pressure. Therefore, the liquid minimizes its surface free by contracting its surface area. The more affine to the liquid the solid surface is, the more spread the liquid on the solid surface (Figure 12A). In contrast, by decreasing the affinity between the two phases, the liquid beads the solid (Figure 12B). Hence, high wettability is achieved when small Cas are measured, whereas low wettability is retrieved when Cas are large.

Figure 12C reports the contact angle-vs-NMR wettability as obtained by the data reported in Bubici et al. [60] for three different gasification produced biochars. In particular, the lower the contact angle, the larger the results regarding the dynamical surface affinity of water (i.e., NMR wettability). 
This possibly suggests that wettability mechanisms from a nano-scale (i.e., FFC NMR relaxometry measurements) up to a macro-scale (i.e., contact angle evaluation) dimension are invariant.
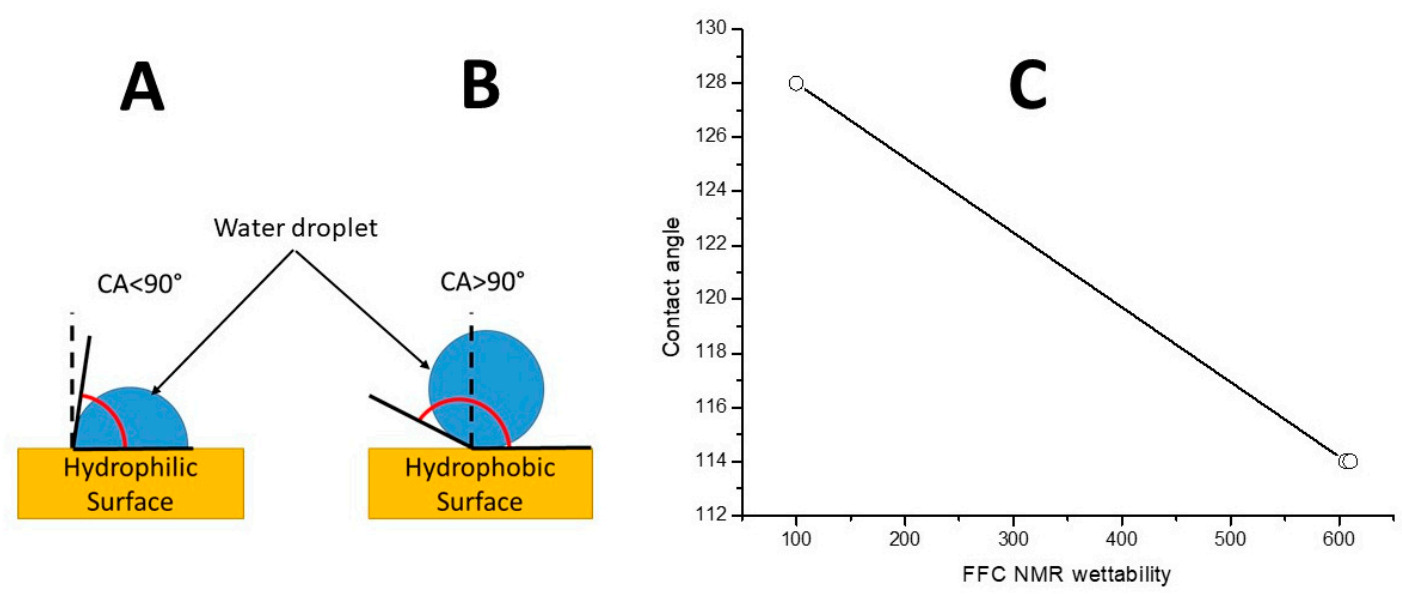

Figure 12. (A). Water droplet spread on a hydrophilic surface. (B). Water droplet beading a hydrophobic surface. (C). Contact angle-vs-NMR wettability as obtained from the data reported in Reference [60]. The full line is only for the eyes. CA stands for contact angle. The shorter the contact angle (e.g., $\mathrm{CA}<90^{\circ}$ ), the higher is the surface hydrophilicity. Conversely, as the contact angle increases (e.g., $\mathrm{CA}>90^{\circ}$ ), the more hydrophobic (or the less hydrophilic) the solid surface.

According to these results, it can be highlighted that the importance of the NMR wettability relies on the possibility to monitor water dynamics at a nanometer length scale. This enables one to predict both the possible transformation mechanisms occurring to biochar as it is applied to soils, and nutrient availability when soils are enriched with biochar [60].

\subsection{The FFC NMR Modeling via Molecular Dynamics Simulations}

The discussion above evidenced that the choice of the right FFC NMR model to apply to soils and soil related materials is left to investigator's sensibility. However, very recently, a new study dealing with the combination between FFC NMR modeling and molecular dynamics (MD) simulations appeared [78]. The authors showed that NMRD profiles and temperature trends can be calculated with a very good approximation by using MD simulations. Accordingly, the right mathematical model to be applied to NMRD data can be chosen on the basis of the results of the aforementioned simulations. The limit of this approach lays in the fact that the authors studied simple ionic liquids. Therefore, their procedure does not account for the complexity of soil systems. In fact, the presence of many different inorganic and organic moieties in soils prevents the application of molecular dynamics simulations due to the enormous computer time required to calculate the trajectories of thousands different nuclei. Very likely, MD simulations could be applied successfully on soils when quantum computing will be easily accessible.

\section{Understanding Soils by Fast Field-Cycling NMR Relaxometry}

\subsection{The Role of Soil Pores in Water Dynamics}

It is well known that the ability of water to infiltrate into soils depends on soil pore sizes [44]. In particular, three different kinds of pores are recognized [79,80]. The "residual pores" $(R P)$ have a size of $\leq 0.5 \mu \mathrm{m}$. Here, strong chemical interactions at a molecular level are supposed to occur between pore wall boundaries and water molecules. Water is strongly trapped in the soil system, thereby becoming unavailable for plant nutrition. Pores with size ranging from 0.5 to $50 \mu \mathrm{m}$ are referred to as "storage pores" $(S P)$. In these pores, water can be retained, but released against gravity. This permits exchanges and diffusion of nutrients within soil pores and, as a consequence, plant nutrition. Finally, 
pores with sizes $\geq 50 \mu \mathrm{m}$ are indicated as "transmission pores" (TP). Here, water is more freely moving than in residual and storage pores. This means that it can be easily leached, thereby leading to nutrient loss and soil fertility reduction.

In the last years, the dynamics of water in the aforementioned soil pores has been validated by NMR relaxometry, either at fixed magnetic field strength or by fast field-cycling setup. In particular, Maccotta et al. [56], Laudicina et al. [62], Pohlmeier et al. [81], Bayer et al. [82], Stingaciu et al. [83], Conte et al. [84], and Haber-Pohlmeier et al. [85,86] reported about the direct relationship between soil pore size and relaxation time values (a detailed mathematical approach is reported in Appendix B). All the aforementioned authors showed that the smaller the soil pore size, the faster the NMR relaxation rate, due to the better efficiency of the ${ }^{1} \mathrm{H}-{ }^{1} \mathrm{H}$ dipolar interactions between water molecules and pore wall boundaries. Moreover, it has been possible to state that the relaxation rate of water in soil pores follows the order: $R P_{\mathrm{H}_{2} \mathrm{O}}>S P_{\mathrm{H}_{2} \mathrm{O}}>T P_{\mathrm{H}_{2} \mathrm{O}}$ which is the inverse of the motion rate, i.e., $R P_{\mathrm{H}_{2} \mathrm{O}}<S P_{\mathrm{H}_{2} \mathrm{O}}<T P_{\mathrm{H}_{2} \mathrm{O}}$. However, soil pore system complexity, where residual, storage and transmission pores coexist in different relative amounts according to soil nature [44], allowed all the aforementioned authors to describe the motion of soil water as bimodal. In other words, water moves in the smallest sized pores by 2D diffusion which can be described as the horizontal motion of water-and nutrients dissolved therein-towards plant roots (Figure 13). Diffusion rate is mediated by the interactions between water molecules and the surface of the pore wall boundaries. The stronger the interactions, the slower the diffusion. For this reason, it is possible to argue that among all the different types of pores, the storage ones are mainly involved in the horizontal transport of water and nutrients towards plant roots.

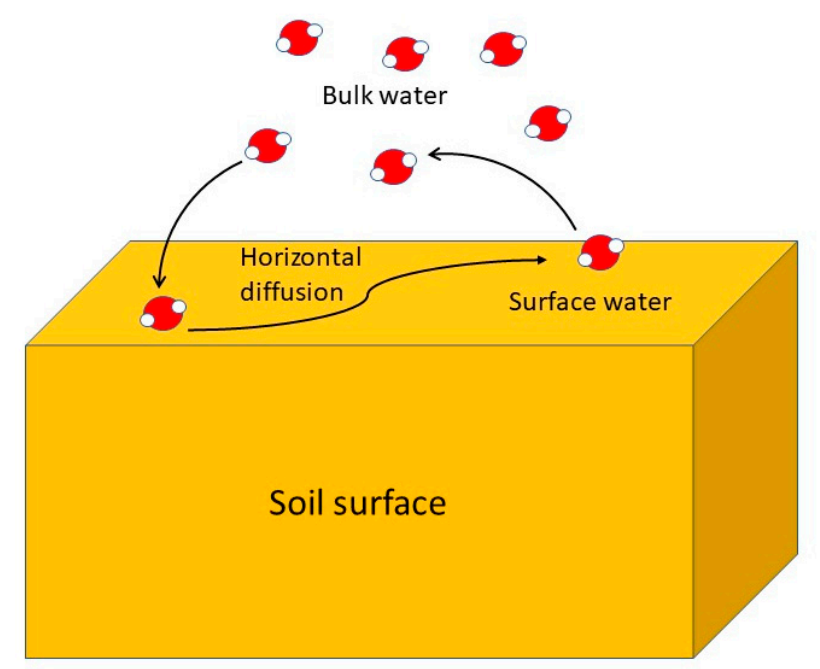

Figure 13. Bimodal water movement into soils. Surface water molecules are hooked to the soil surface being subjected to horizontal diffusion. When surface water "jumps" to the bulk, one of the bulk molecules replace it. The frequency of the "jumps" and the duration of the horizontal diffusion are affected by the strength of the interactions between water molecules and soil surface.

Water molecules "hooked" on the soil surface can be replaced by bulk water molecules. For this reason, while the former "jump" from the surface to move to the bulk, the latter move on the soil surface, thereby contributing to water diffusion (Figure 13). The frequency of the 3D jump-also referred to as vertical motion of water and dissolved nutrients-is affected by the strength of the interactions between water and pore wall boundaries. The stronger the interactions, the lower the 3D jump frequency. According to this mechanism, it is possible to state that the 3D jumps are common in soils richer in transmission pores, thereby allowing a reduction in soil fertility as a consequence of water and nutrient leaching towards the lowest soil horizons. 


\subsection{FFC NMR to Quantify Soil Erosion}

Soil erosion is a serious problem threatening both land management sustainability and water resource development. It is due to the expansion of agricultural areas because of an increasing need of food supply.

Despite the recognition of soil erosion environmental hazard, there is still a lack of homogeneity in the methodologies used to quantify soil loss associated with the development of agriculture and reduction in forest areas.

Traditionally, the typical techniques applied to monitor soil erosion are short-duration field monitoring programs employing erosion pins and erosion plots, while longer-term experimental studies use soil loss plots, the interpretation of repeated aerial photographs, and the use of satellite imagery [87]. All of the aforementioned techniques are limited by problems related to spatial and temporal variability, operational difficulties, costs and questionable reliability of the resulting data [87]. For this reasons, the more reliable technique based on the artificial radionuclide ${ }^{137} \mathrm{Cs}$ has been developed and applied worldwide [87]. The attraction for ${ }^{137} \mathrm{C}$ s investigations lies in the considerations that it has been introduced worldwide in the atmosphere as a consequence of the development of nuclear weapons between the fifties and the seventies of the 20th century. Due to both precipitation phenomena and its strong affinity for soil and sediment particles, ${ }^{137} \mathrm{Cs}$ is now present on a global scale. Therefore, monitoring its fate provides useful information on soil transformations [87]. However, ${ }^{137} \mathrm{Cs}$ analyses require special equipped labs as well as special precautions because of its radioactive properties. For this reason, the question on the possibility to use FFC NMR relaxometry to quantify soil erosion has risen $[57,88,89]$. The advantage of the technique is its low cost, the handling of non-radioactive nuclei, and its worldwide diffusion. In fact, most of the NMR labs are also equipped with FFC NMR benchtop machines. However, the little number of NMR labs dealing with environmental problems, and especially soil science, may be the bottleneck for the development of FFC NMR in monitoring soil erosion.

In order to understand how FFC NMR relaxometry can be applied to account for soil erosion, let us consider that the vertical motion described in Section 7.1 is not only related to water and nutrient leaching towards the lowest soil horizons, but also to the surface-water macroscopic flows. Both aforementioned water movements can be described by the concept of "connectivity" [57,88,89]. The latter refers to all the 'processes involving a transfer of matter, energy, and/or organisms within or between elements of a system such as landscapes, basins and soils' [90]. This definition implies that a transport vector, such as water, must be involved in moving materials over a range of space and time scales, thus permitting investigations of the effects of heterogeneities of complex and inhomogeneous physical systems [91-93].

Three different types of connectivity have been recognized [94]: (i) landscape connectivity, related to the physical coupling of landforms; (ii) hydrological connectivity, referred to the water transfer through the basin; (iii) sedimentological connectivity, related to the sediment transfer. Recently, the landscape connectivity has been also referred to as structural connectivity [95]. This represents the extent to which landscape units are contiguous or physically linked to each other [95]. Moreover, a functional connectivity has also been introduced [95]. It accounts for how the interactions between structural characteristics may affect geomorphological, hydrological and ecological processes [95].

Both structural and functional connectivities have been qualitatively recognized in the relaxograms acquired by FFC NMR on water saturated soil samples [88]. In fact, the shape of the relaxograms was associated to the structural connectivity, while the position of the bands in a relaxogram was related to the functional connectivity [88]. The quantification of both structural and functional connectivity can be achieved by a mathematical empirical model developed by Conte and Ferro [57,89]. In particular, the non-exceeding empirical cumulative frequency curve, $F\left(T_{1}\right)$, obtained by the integration of any relaxogram (Figure 14), provides two different types of information. 


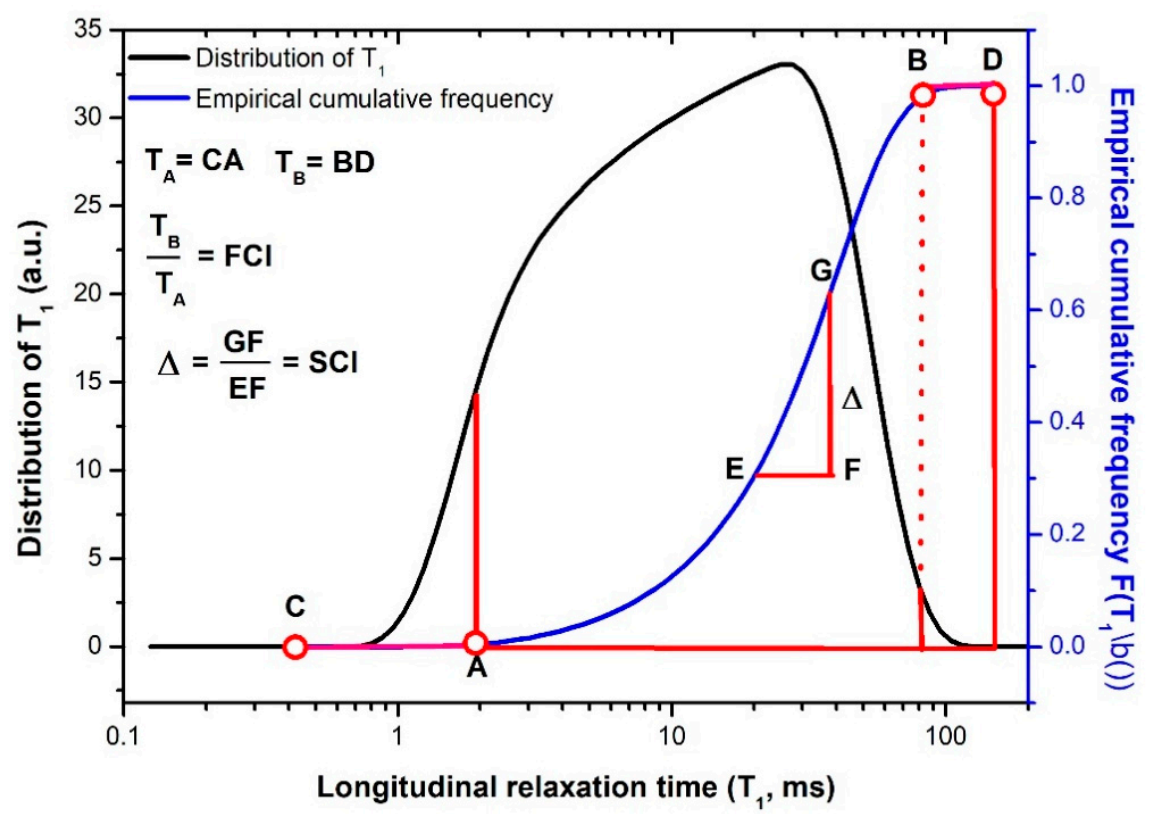

Figure 14. The black curve is the relaxogram acquired at the proton Larmor frequency of $30 \mathrm{MHz}$ for one of the soils described in Reference [89]. This relaxogram has never been published, and is only discussed in the aforementioned reference. The blue curve is the empirical cumulative frequency obtained by the integration of the relaxogram. The segments $C A$, having length $\mathrm{T}_{\mathrm{A}}$ (expressed in $\mathrm{ms}$ ), and $\mathrm{BD}$, with the length $\mathrm{T}_{\mathrm{B}}$ (in $\mathrm{ms}$ ), represent the amount of fast- and slow-relaxing nuclei, respectively, corresponding both to $1 \%$ of the empirical cumulative frequency curve. The ratio $T_{B} / T_{A}$ is the functional connectivity index (FCI). The slope $\Delta=\mathrm{GF} / \mathrm{EF}$ is the structural connectivity index (SCI).

Let us arbitrarily divide the empirical cumulative frequency curve in three parts: $F\left(T_{1}\right)<0.01$, $0.01<F\left(T_{1}\right)<0.99$, and $F\left(T_{1}\right)>0.99$. The two extremes represent the fast- $\left(F\left(T_{1}\right)<0.01\right)$ and slow$\left(F\left(T_{1}\right)>0.99\right)$ relaxing nuclei, respectively. The former belong to water molecules constrained in residual pores, while the latter are from water molecules moving in transmission pores. All the ${ }^{1} \mathrm{H}$ nuclei in the interval $0.01<F\left(T_{1}\right)<0.99$ are considered to belong to water molecules moving in storage pores. The longitudinal relaxation time interval corresponding to $F\left(T_{1}\right)<0.01$ is represented in Figure 14 by the segment $C A$ having length $T_{A}$, while the segment $B D$ with length $T_{B}$ corresponds to $F\left(T_{1}\right)>0.99$ (Figure 14). The $\mathrm{T}_{\mathrm{B}} / \mathrm{T}_{\mathrm{A}}$ ratio can be considered as the relative amount of freely moving water over the water strongly bound to the wall boundaries of the smallest pores in soil. The larger the pore size, the higher the $T_{B} / T_{A}$ ratio as a consequence of the huger amount of unconstrained water. Conversely, as pore size decreases, water molecules become more restrained and the $T_{B} / T_{A}$ ratio decreases. According to this, it is possible to state that the $T_{B} / T_{A}$ ratio can be considered as a measure of the functional connectivity because its value is related to the way water molecules interact with soil particles. Therefore, we can indicate the aforementioned ratio as the functional connectivity index (FCI).

In order to define the structural connectivity, the middle part of the empirical cumulative frequency distribution can be used. In fact, the $0.01<F\left(T_{1}\right)<0.99$ interval, which corresponds to water molecules moving in storage pores, represents the main structure of the soil, so that it may suitably represent the spatial pattern inside the soil.

According to Laudicina et al. [88], the width of the relaxogram is correlated to the total amount of pores in the system, whereas the position of the maxima refers to the contribution of residual, storage, and transmission pores. Therefore, it can be assumed that the $F\left(T_{1}\right) \mathrm{S}$-shaped curve weights the contribution of the storage pores over the other two types of pores. Hence, it is possible to define a structural connectivity index (SCI) as the ratio between the coefficient of variation of the relaxation 
times corresponding to the empirical cumulative frequency values in the range 0.01 to 0.99 , that is, the slope $\Delta=\mathrm{GF} / \mathrm{EF}$ in Figure 14 .

Noticeably, both FCI and SCI appear independent of the applied magnetic field [57]. Therefore, the measurement of the aforementioned indexes can be achieved by using the magnetic field strength which ensures the best NMR experimental sensitivity. Moreover, the FCI and SCI indexes can be also obtained by the evaluation of $T_{2}$ relaxograms. However, this is yet to be verified.

Having introduced the FCI and SCI indexes, let us now reveal why they can be a measure of soil erosion.

Erosion involves changes in soil structure and, hence, in soil pore distribution [96]. For this reason, water molecules change their motion rate according to the size of the pores. As a consequence, the FCI and SCI values also change, thereby allowing the monitoring of soil erosion (ongoing study) and permitting one to apply what is needed to restore soil productivity and functions.

\subsection{The Behaviour of Dissolved Organic Matter (DOM)}

Dissolved organic matter (DOM) plays a very important role in many biogeochemical mechanisms and responses to changes in ecological processes. As an example, it is involved in the solubilization and transport of both inorganic [97] and organic molecules and colloids [98,99], micronutrient availability [100], rock weathering [101], pedogenesis of topsoils and subsoils [102,103], soil water repellence [73], and soil texture [104].

Due to its environmental importance, DOM chemical-physical properties have been studied for a long time. As an example, many models have been suggested to explain the conformational behavior of dissolved organic matter, such as the linear macromolecular polyelectrolyte hypothesis [105], the supramolecular assemblies of molecules stabilized by weak interactions [106], the heterogeneous Donnan gel phases [107], or the mixture of supra and macromolecules [108].

The complexity and flexibility of DOM are considered to be responsible for its ability to enhance solubility of hydrophobic organic compounds, its capacity to decrease water surface tension, or its capability to trap and transport nutrients across the space [109].

Liquid water can be considered as a three-dimensional network of molecules held together by transient hydrogen bonds [110]. Once organic matter is dissolved, the $\mathrm{H}$-bond network is altered, thereby leading to a new H-bond network which is stabilized by the presence of the dissolved organic matter.

When heating/cooling cycles occur (that is a rule in nature), DOM structure is altered [111] and changes in DOM sorption/desorption capacities can be observed [112]. The temperature dependence of the aforementioned changes were attributed to the dynamic re-arrangement of the water clusters around DOM [113]. This latter hypothesis was verified by NMR relaxometry with fast field-cycling setup [109]. It came out that a delay (also referred to as hysteresis) in re-establishing water network around DOM occurs as a result of the temperature fluctuations. Hysteresis appeared to be more pronounced when more hydrophilic dissolved organic matter was accounted for. The relaxometry results also supported the view that soil DOM consists of a hydrophobic rigid core surrounded by amphiphilic and polar molecules progressively assembled, and forming an elastic structure able to mediate the reactivity of the whole dissolved organic matter [109].

The relaxometry with the FFC setup was also helpful in monitoring the changes in the chemical nature of DOM upon interaction with montmorillonite (M) and kaolinite (K) [84]. In particular, the typical spectroscopic investigations (i.e., FT-IR and cross polarization (CP) magic angle spinning (MAS) ${ }^{13} \mathrm{C}$ NMR spectroscopy) indicated that montmorillonite revealed a higher affinity for more hydrophilic -OH containing DOM moieties, whereas kaolinite adsorbed preferentially hydrophobic DOM components. The relaxometric results showed a huge simplification of the chemical nature of DOM after adsorption on montmorillonite as compared to the adsorption on kaolinite. In particular, the number of different DOM relaxation components after adsorption was in the order $\mathrm{K}>\mathrm{M}$ (Figure 15). In order to explain the relaxometric behavior reported in Figure 15, it must be reminded 
that dissolved organic matter is a mixture of molecules that result from the degradation of humus, biomasses, plant materials, and root exudates, all of them involved in superstructures with a wide distribution of different molecular sizes [114]. After adsorption on montmorillonite and kaolinite, the residual DOM organic moieties re-aggregate to form new superstructures. Those obtained after interaction with montmorillonite are the simplest (Figure 15B) due to the inter-layer adsorption ability of montmorillonite which enabled the retention of a larger number of organic matter than kaolinite.

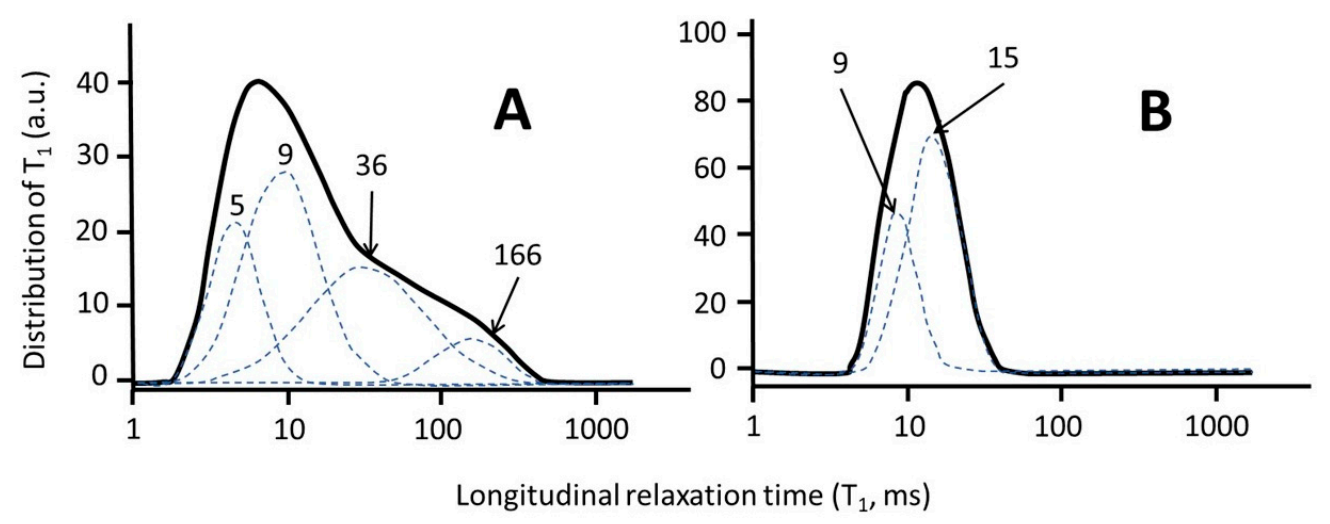

Figure 15. (A). Relaxogram of dissolved organic matter after interaction with kaolinite. (B). Relaxogram of dissolved organic matter after interaction with montmorillonite. The dashed lines represent the different $T_{1}$ components as obtained by deconvolution. This figure has been reproduced from Reference [84] with the permission of Elsevier.

\subsection{Water Behavior in the Presence of Inorganic Ions: The Dynamics of Soil Solution}

Water is crucial to the movement of dissolved species in the environment. Indeed, it is involved in most biogeochemical processes and affects the properties of bio-systems from microscale to macroscale [44]. In order to retrieve information on the role played by water in nutrient dynamics towards plant roots, relaxometry with fast field-cycling setup has been applied on water solutions containing dissolved salts at different concentrations.

Dissolution of a solute in a solvent is indicated as solvation process which is referred to as hydration when the solvent is water. Hydration leads to formation of water shells around the solute. In particular, two different hydration shells are usually recognized $[115,116]$. The innermost shell, where $\mathrm{H}_{2} \mathrm{O}$ directly interact with the solute, is made by immobilized molecules. A second hydration shell made by more disordered and mobile $\mathrm{H}_{2} \mathrm{O}$ molecules surrounds the former layer. As solutions become progressively diluted, a third outermost water shell, referred to as bulk, can also be recognized [117]. The frequency of diffusional motion in bulk water is larger than in the first and second hydration shells. The size of each hydration shell depends on the physico-chemical features of the solutes [115-118]. In particular, the larger the charge density of the ions dissolved in water, the thinner is the hydration layer due to the strong effects of the electrical field generated by the ions [115-118]. In other words, water molecules are in the closest proximity of the ions. Upon increment of salt concentration, the space available for water in the bulk progressively reduces, thereby restricting the presence of free moving water. At the saturation point, no free moving bulk water is present.

Water molecules in the innermost shells can be exchanged with the ones in the outermost shell. The rate of exchange is affected by the strength of the water-solute interactions. In more detail, the stronger the interactions (as in the case of large solute concentrations or ions with high charge density), the lower the water mobility. Conversely, as the interaction strength weakens (low concentrated solutes, or low charge density ions), water mobility increases, and the exchange rate raises [110]. Water molecules strongly interacting with solutes are arranged in an ice-like shell where they are not flexible enough to accomplish the H-bonds within the first hydration shell. For this reason, strengthening of the $\mathrm{H}$-bonds between the first and the second hydration shell occurs. By weakening the interactions 
between ions and water, water molecules in the first hydration shell become more flexible. As a consequence, the first shell intra-layer $\mathrm{H}$-bonds strengthen, while the first-second shell inter-layer ones weaken [117]. Ions weaken the first shell intra-layer interactions, thereby allowing stronger first-second shell inter-layer interactions, which are referred to as structure makers or kosmotropes (Figure 16A). Water molecules around kosmotropic ions form a low-density ice-like layer [110,119-123]. Ions which are incapable of weakening the first shell intra-layer interactions, thus leading to weaker first-second shell inter-layer interactions, are indicated as structure breakers or chaotropes (Figure 16B). Water molecules generate high-density microdomains around chaotropic ions [110,119-123].

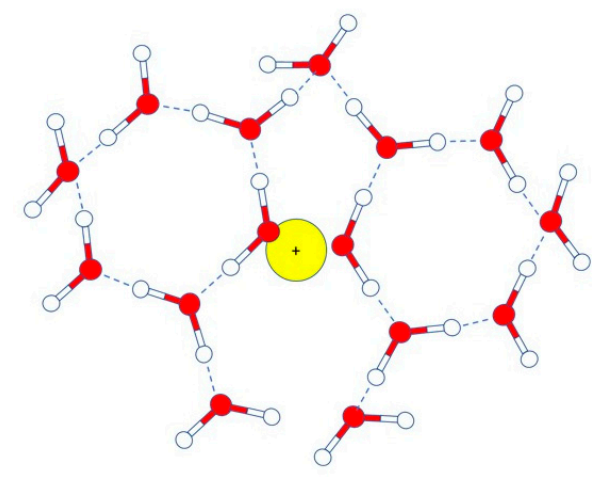

A

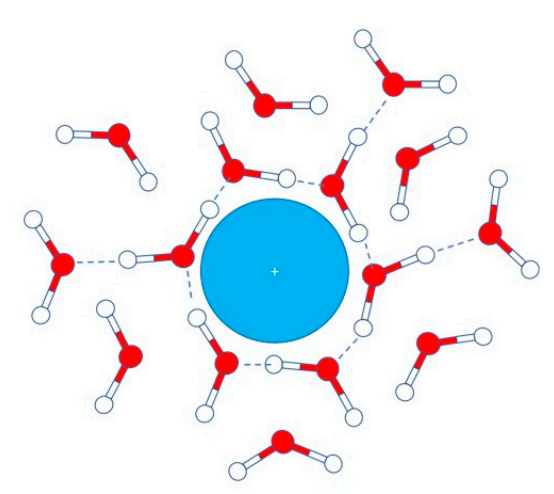

B

Figure 16. (A). Low-density ice-like layer around a kosmotropic ion. (B). High-density water around a chaotropic ion.

Fast field-cycling NMR relaxometry has been able to reveal the properties of water molecules in the hydration shells of several salts chosen for their natural presence in the soil solution. In particular, solutions containing different concentrations of $\mathrm{KCl}, \mathrm{NaCl}, \mathrm{CaCl}_{2}, \mathrm{~K}_{2} \mathrm{CO}_{3}, \mathrm{NaNO}_{3}$ and $\mathrm{NH}_{4} \mathrm{NO}_{3}$ have been investigated.

Among the aforementioned salts, potassium chloride revealed a chaotropic nature, in the range of concentrations from very diluted up to saturation. The opposite behavior was shown in the same concentration range by $\mathrm{NaCl}, \mathrm{CaCl}_{2}$, and $\mathrm{K}_{2} \mathrm{CO}_{3}$, whereas $\mathrm{NaNO}_{3}$ and $\mathrm{NH}_{4} \mathrm{NO}_{3}$ showed either a chaotropic or a kosmotropic nature depending on their concentration. More in detail, they behaved as chaotropes up to the concentration of $4 \mathrm{M}$. Conversely, they showed a kosmotropic behavior above the aforementioned concentration. From a qualitative standpoint, the different effects could be explained considering the prevalence of the chaotropic nature of the cations (either $\mathrm{Na}^{+} \mathrm{or} \mathrm{NH}_{4}{ }^{+}$) when concentrations were $<4 \mathrm{M}$ and by the prevalence of the kosmotropic nature of nitrate when salt concentration was $>4 \mathrm{M}$.

The model discussed in this sub-section has been confirmed in Payne et al. [41], Yadav et al. [124], Farashishiko et al. [125], and Sharma and Chandra [126].

\subsection{A FFC NMR-Based Model for Nutrient Dynamics in Soils}

According to the water behavior depicted above, an FFC NMR-based model for nutrient dynamics towards plant roots in soil solution can be suggested.

As already stated, structure maker solutes are surrounded by low-density water (LDW) microdomains, whereas structure breaker solutes generate high-density water (HDW) microdomains [110,119-123].

The LDW microdomains are due to the low flexibility of water molecules around kosmotropes. For this reason, water molecules are forced towards an ice-like behavior, with each molecule occupying a fixed position in order to fulfill the requirements necessary for the formation of interlayer H-bond. By increasing the distance from the solute, water flexibility increases as well. This means that the LDW 
domain progressively switches to a denser and more disordered domain, with water molecules laying closer to each other (Figure 17). The gradual switch from the LDW to the HDW domains is affected by the intensity of the local solute-generated electric field. For this reason, it can be assumed that the size of the LDW micro-domain increases with the intensity of the electric field. Noteworthy, water molecules in the LDW domain can exchange with those in the HDW domain, while the separation among the domains is maintained (Figure 17).

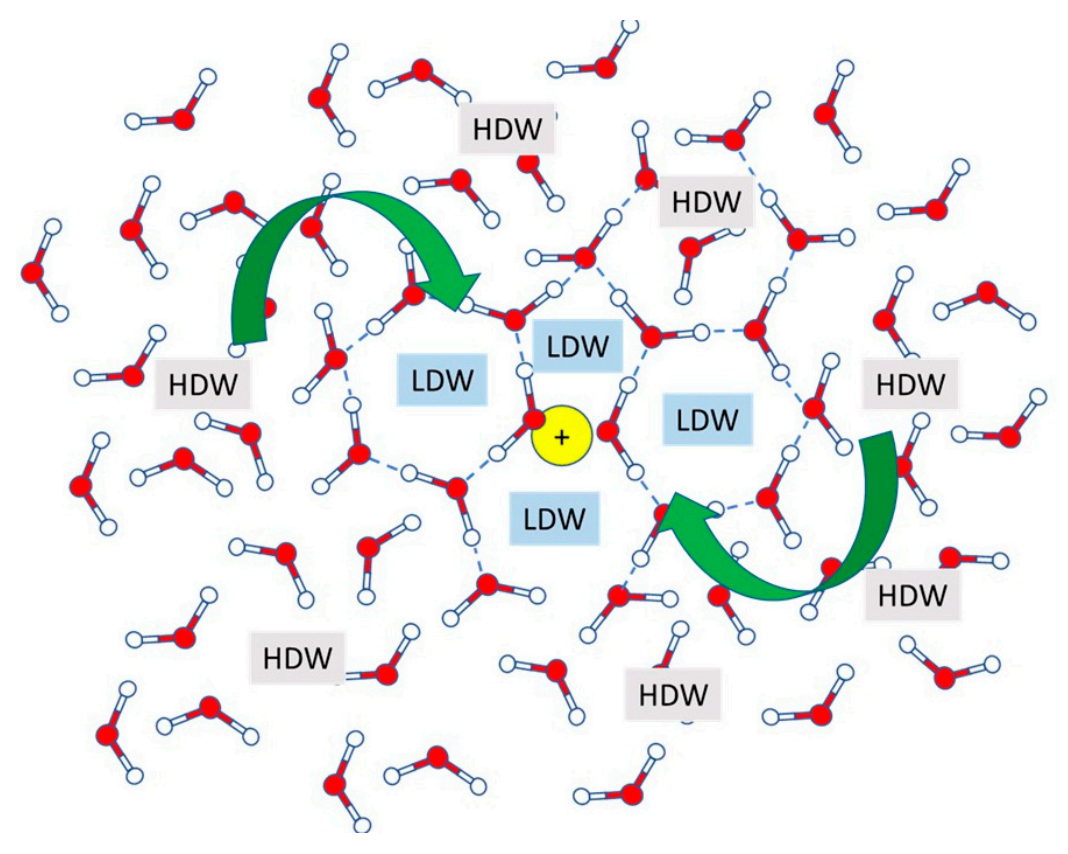

Figure 17. Kosmotropic ion dissolved in water. This is surrounded by a low-density water (LDW) microdomain which moves towards a high-density water (HDW) microdomain as the distance from the ion increases. The green arrows indicate the molecular exchanges between HDW and LDW domains.

As water surrounds a chaotrope, its molecular organization can be conceivably considered more disordered because of the its larger flexibility in the first hydration shell. As a consequence, the number of water molecules that can be packed together in the same volume unit is larger than in the case of the structure maker solutes. Hence, a high-density water domain is generated. While a progressive transition LDW $\rightarrow$ HDW has been described for the structure maker solute, no such a transition can be hypothesized around the structure breaker solute. In other words, water molecules behave as a bulk also in the nearest proximity of the structure breaker solute [119-123]. When a mixture of both kosmotropes and chaotropes is accounted for, an exchange of water molecules among LDW and HDW domains occurs. However, since the motion of water molecules cannot be independent from that of the dissolved solutes, the latter randomly move together with water in order to let the solution reach a water average density homogeneity that may ensure a maximum entropy value, thereby leading also to a solute concentration homogenization throughout the solution. A complete discussion about the thermodynamics of the aforementioned water behavior can be found in Holtzer's papers [127,128].

Let us now consider how water can be organized in the rhizosphere, which is 'the zone that includes the soil influenced by the root along with the root tissues colonized by microorganisms' [129]. Here, root exudation, respiration, redox reactions, and nutrient supply appear to be the main factors affecting $\mathrm{pH}$ changes $[130,131]$. In particular, the amount of $\mathrm{H}^{+}$or $\mathrm{OH}^{-}$in the rhizosphere strongly depend on both the ions crossing the plasma membrane towards the soil and the ions taken up by the plants from the soil. In fact, according to their nature, all the ions coming from the intake-outtake flux must be counterbalanced by either $\mathrm{H}^{+}$or $\mathrm{OH}^{-}$[131]. As an example, it has been well established that plants absorbing nitrogen in the form of nitrate tend to raise the $\mathrm{pH}$ in the rhizosphere [132,133]. Conversely, plants absorbing nitrogen in the form of ammonium or $\mathrm{N}_{2}$ tend to lower the rhizosphere 
$\mathrm{pH}[132,133]$. However, it must be also pointed out that the degree of the $\mathrm{pH}$ changes depends on the type of plant $[130,134]$.

Having acquainted that the composition of rhizosphere solution is very rich in ions, it is possible to state that, in the rhizosphere, water molecules tend to assume the high-density liquid form [135]. In fact, computer simulation studies revealed that the ability to organize water molecules in ordered clusters does not depend only on the charge density of the ions, but also on the solution ionic strength [135]. In other words, an increase in the charge concentration generates kosmotropic conditions, thereby leading water molecules to behave like structured ice [135].

The low-density water domains in the rhizosphere may exchange with the high-density water domains outside the rhizosphere in order to drive water density towards homogeneity, thus ensuring entropy maximization $[127,128]$. As a consequence, movement of solutes (such as $\mathrm{Na}^{+}, \mathrm{K}^{+}$and $\mathrm{NH}_{4}{ }^{+}$, that are well-recognized plant nutrients) from/to plant roots can be achieved.

Let us concentrate, now, on the organization of water on soil surface. Due to the presence of hydrogen bond donors/acceptors as well as electron-poor moieties, water molecules hooked on soil surface form a thin ice-like film where LDW can be recognized [136]. The kosmotropic effect of the solid soil surface reduces with the distance, and so activates the 3D "jumps" described in Figure 13. The jump frequency depends on soil wettability which, in turn, is affected by chemical nature of natural organic matter (NOM) [84,109]. For this reason, the higher the wettability, the stronger the surface affinity of $\mathrm{H}_{2} \mathrm{O}$ molecules, thereby lowering the number of the possible 3D jumps. At the same time, the 2D diffusion depicted in Figure 13 predominates. The latter is mediated by the formation/demolition of soil-water and water-water interaction dynamics. As reported above, water molecules do not move "alone". They also transport solvated solutes. Therefore, the dynamics of the solutes from/to the solid soil surface can be explained by the increasing of the solvation effect (see sub-section below) as water moves from the LDW to the HDW domains [110,119-123,136].

Shrinking together the dynamics for the rhizosphere and the soil surface reported above, it is possible to summarize the mechanism for nutrient transport as reported in Figure 18.

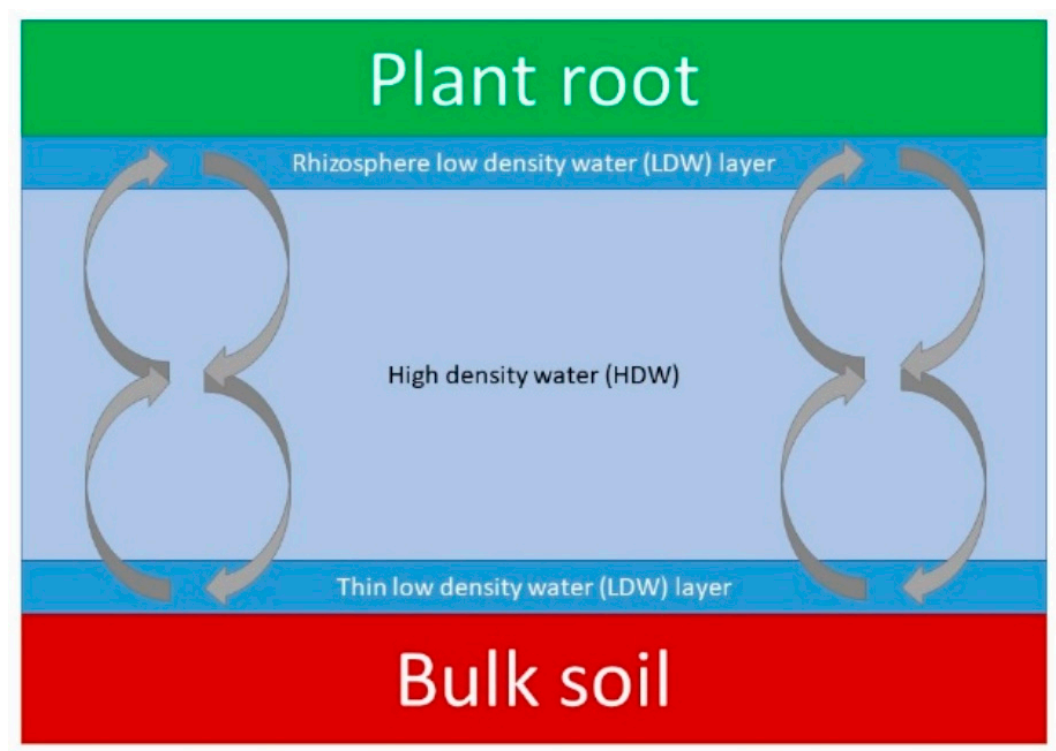

Figure 18. Mechanism for nutrient fluxes. Due to the LDW $\rightleftarrows$ HDW equilibrium occurring on bulk soil surface, the nutrients leave soil surface to enter the soil solution. Afterwards, due to a similar LDW $\rightleftarrows$ HDW equilibrium occurring on the root surface, they leave the soil solution to enter the rhizosphere solution from where they can be taken up by plant roots. The grey arrows represent the LDW $\rightleftarrows$ HDW equilibria. 
Three different water density zones can be recognized (Figure 18). Low-density water layers occur on both soil and root surfaces, while a high-density water layer is identifiable in the soil solution that is the farthest from the two surfaces. Owing to the different densities, the LDW $\rightleftarrows$ HDW equilibrium occurs. This also allows the movement of the inorganic/organic systems adsorbed on both plant roots and soil surfaces. Following the aforementioned equilibrium, the nutrients reaching the rhizosphere solution can then be taken up by plant roots to satisfy plant metabolism.

\subsection{The Mechanism of Soil Ionic Exchange Capacity: The FFC NMR Relaxometry Point of View}

Although it has not explicated in the sub-sections above, the mechanism suggested for nutrient transport can also explain soil ionic exchange capacity. In fact, dissolution of a solute in water occurs as a consequence of hydration. This should be considered as a true reaction where the solute has to compete with $\mathrm{H}_{2} \mathrm{O}$ molecules for the interactions with other $\mathrm{H}_{2} \mathrm{O}$ molecules. The weaker the H-bonds between water molecules, the easier it is for the solute to build hydration shells and, hence, to dissolve. However, water domains in which H-bonds are weak are also denser than those where H-bonds are strong. Therefore, it is conceivable that solutes preferentially react with $\mathrm{H}_{2} \mathrm{O}$ molecules in the HDW domains [110,119-123]. Due to this, it is conceivable that solutes adsorbed on the solid soil surfaces and included in a surficial LDW domain tend to move away from the surface in order to react with the water molecules belonging to the farthest HDW domains. In addition, the solutes (e.g., cations and anions) removed from the surface are replaced by other solute molecules moving from the HDW domain.

\section{Conclusions and Perspectives}

We are well aware that fast field-cycling NMR relaxometry is a technique that remains accessible to a small number of specialists. A knowledge of deep quantum mechanics is needed together with the ability to handle electronics, circuits, and programming languages. FFC NMR results are not as easily readable as those from spectroscopy, thereby making the former less popular in soil science than the latter, which is very often misused in the field [3,11,12,137].

Within the present review, we have summarized the main and most recent soil science findings retrieved by FFC NMR relaxometry. The focus point is surely the application of the right model for data interpretation. Although the plethora of models described here gives the idea of an exit-less labyrinth, we have clearly shown that the combination between FFC NMR results and the data from other soil science investigations (e.g., soil texture, $\mathrm{pH}$, soil organic matter nature and content, electron spin resonance results, microscopy etc.) strongly facilitates the choice of the right mathematical model to be applied.

FFC NMR results revealed a paramount importance to unveil molecular mechanisms occurring in soil solution which, in turn, can be used to reinterpret the phenomena arising on the surface of plant roots. In particular, the main results showed two main water movements on the solid surfaces: a 2D diffusion and a 3D out-of-surface motion. While the former is responsible for the distribution of solutes and water on the surfaces, the latter is involved in the transport phenomena toward plant roots and nutrient leaching. Transport phenomena can be efficaciously explained by considering the chaotropic or kosmotropic nature of solutes which allow the identification of an HDW and a LDW domain. The LDW domain is generated by ice-like water which is due to (i) water interacting with kosmotropic solutes, (ii) water in kosmotropic conditions (i.e., large solute concentrations), or (iii) water interacting with solid surfaces. The HDW domains are generated by both chaotropic solutes and chaotropic conditions (i.e., low solute concentrations). Solute movement is affected by water solvation efficiency, which, in turn, depends on the LDW and the HDW domains. The former reduce water solvation efficiency as compared to HDW domains. Consequently, solute transport in soils is affected not only by random water movements but also by the different solubility of the solute in the different water density domains.

The model of water dynamics suggested above can be a subject of concern, as it is based on the combination of the interpretation of FFC NMR relaxometry data and those suggested by 
Wiggins [119-123], Gallo et al. [135], and Henderson [136]. However, there are few papers where a negligible effect of solutes on the 3D H-bond network of water molecules is reported $[138,139]$. Therefore, further research is needed to better clarify the role of low-density and high-density domains in soil and rhizosphere water and regarding nutrient mobility in soil systems.

Author Contributions: Both authors equally contributed to the paper. Both authors have read and agreed to the published version of the manuscript.

Funding: This study received no external funding.

Acknowledgments: The authors acknowledge the help of Gianni Ferrante, Rebecca Steele, and Moreno Pasin from Stelar Srl for their help in providing the FFC NMR relaxometry analyses of the quartz sand described in the present review paper. Anna Micalizzi from University of Palermo is acknowledged for her technical assistance in preparing samples and performing experiments on some of the soil samples reported here.

Conflicts of Interest: The authors declare no conflict of interest.

\section{Appendix A}

In Section 3, Section 4, and Section 6, experimental data concerning a quartz sand saturated with Milli-Q grade water have been discussed. These data have never been published. Therefore, here the details of the experiments performed on this model system are reported. The quadrupolar-less nuclei quartz sand (CAS N. 14808-60-7, 50-70 mesh particle size) was purchased from Sigma (Milan, Italy) and used without any pre-treatment. The Milli-Q grade water (resistivity of $18.2 \mathrm{M} \Omega \mathrm{cm}$ ) was produced by using a Millipore system (Millipore Corporation, Billerica, MA, USA). The sample for the FFC NMR relaxometry experiment was prepared as a slurry according to Reference [56]. ${ }^{1} \mathrm{H}$ NMRD profiles (i.e., longitudinal relaxation rates $R_{1}$ or $1 / T_{1}$ vs proton Larmor frequencies) were acquired on a Stelar Spinmaster FFC 2000 relaxometer (Stelar s.r.l., Mede, PV, Italy) at a constant temperature of $25^{\circ} \mathrm{C}$. The field-switching time was $3 \mathrm{~ms}$, while the spectrometer dead time was $15 \mu \mathrm{s}$. The proton spins were polarized at a polarization field $\left(\boldsymbol{B}_{P O L}\right)$ corresponding to a proton Larmor frequency $\left(\omega_{L}\right)$ of $29 \mathrm{MHz}$ for a period of polarization $\left(T_{P O L}\right)$ of $0.2 \mathrm{~s}$. A recycle delay of $2 \mathrm{~s}$ was always applied. The longitudinal magnetization evolution was recorded at values of a relaxation magnetic field $\left(\boldsymbol{B}_{R L X}\right)$ corresponding to $\omega_{L}$ comprised in the range of 0.015 to $35 \mathrm{MHz}$. The NMR signal was acquired with four scans for a period of time $(\tau)$ arrayed with 32 values, chosen in an exponential progression for the covering of the entire relaxation curve of interest. Finally, a ${ }^{1} \mathrm{H} 90^{\circ}$ pulse was used at the start of the acquisition period contemporarily to an acquisition magnetic field $\left(\boldsymbol{B}_{A C Q}\right)$ corresponding to a $\omega_{L}$ of $16.2 \mathrm{MHz}$. The observable magnetization was revealed as free induction decay (FID) with a time domain of $100 \mu \mathrm{s}$ sampled with 1000 points.

\section{Appendix B}

The first explanation of the relationship between porosity of a porous medium and longitudinal relaxation was given by Brownstein and Tarr [140]. In particular, for wet micro- or nano-porous materials the relaxation rates $R_{1}$ can be related to the fraction of water molecules interacting with the pore surface $\left(f_{s}\right)$ by the equation [38]:

$$
R_{1}=R_{w}+f_{s}\left(R_{s}-R_{w}\right)
$$

Here, $R_{w}$ is the relaxation rate of the bulk water. It is a constant (i.e., ca. $0.4 \mathrm{~s}^{-1}$ ) in the whole proton Larmor frequency range $(0.01-40 \mathrm{MHz})$ usually applied when the typical fast field-cycling NMR relaxometry equipment is used [20]. $R_{S}$ is the intrinsic relaxation rate for the water moving on the porous surface.

$R_{1}$ can lead back to the porosimetric parameters via the following equations [38]:

$$
R_{1}=R_{w}+\rho_{1} \frac{S}{V}
$$




$$
\begin{gathered}
R_{1}=R_{w}+\rho_{1} \frac{\alpha}{D} \\
R_{1}=R_{w}+\lambda \frac{\alpha}{D}\left(R_{s}-R_{w}\right)
\end{gathered}
$$

In Equations (A2) to (A4), $\rho_{1}$ is the longitudinal surface relaxivity (in $\mathrm{cm} \mathrm{s}^{-1}$ ). It characterizes the ability of the porous surface to facilitate the longitudinal relaxation in the nearby fluid molecules. Its value is affected by surficial quadrupolar systems. $S=m A_{s}$ where $m$ is the sample mass (in g) and $A_{s}$ is the specific surface area (in $\mathrm{cm}^{2} \mathrm{~g}^{-1}$ ). $V$ is the total pore volume of the saturated porous system, $\alpha$ is a pore shape parameter, $D$ is the average pore diameter, and $\lambda$ is the thickness of the water layer on pore walls (usually set as large as $0.3 \mathrm{~nm}$ ). By combining Equations (A1) to (A4), it can be observed that $D=\lambda\left(\frac{\alpha}{f_{s}}\right)$ and $f_{s}=\lambda\left(\frac{S}{V}\right)$. The inverse relationship between $R_{1}$ and pore size $(D)$ given in Equation (A4) explains what is reported in the discussion above.

\section{References}

1. Simpson, A.J.; Simpson, M.J.; Soong, R. Nuclear magnetic resonance spectroscopy and its key role in environmental research. Environ. Sci. Technol. 2012, 46, 11488-11496. [CrossRef] [PubMed]

2. Farooq, H.; Courtier-Murias, D.; Soong, R.; Bermel, W.; Kingery, W.; Simpson, A. HR-MAS NMR spectroscopy: A practical guide for natural samples. Curr. Org. Chem. 2013, 17, 3013-3031. [CrossRef]

3. Conte, P.; Spaccini, R.; Piccolo, A. State of the art of CPMAS13C-NMR spectroscopy applied to natural organic matter. Prog. Nucl. Magn. Reson. Spectrosc. 2004, 44, 215-223. [CrossRef]

4. Jameson, C.J. Gas-Phase NMR Spectroscopy. Chem. Rev. 1991, 91, 1375-1395. [CrossRef]

5. Elyashberg, M. Trends in Analytical Chemistry Identification and structure elucidation by NMR spectroscopy. Trends Anal. Chem. 2015, 69, 88-97. [CrossRef]

6. Simpson, A.J. Environmental NMR. Magn. Reson. Chem. 2015, 53, 633-634. [CrossRef]

7. Lurie, D.J.; Aime, S.; Baroni, S.; Booth, N.A.; Broche, L.M.; Choi, C.; Davies, G.R.; Ismail, S.; Dara, Ó.; Pine, K.J. Comptes Rendus Physique Fast field-cycling magnetic resonance imaging Imagerie de resonance magnétique en champ cyclé. Comptes Rendus Phys. 2010, 11, 136-148. [CrossRef]

8. Bastawrous, M.; Jenne, A.; Tabatabaei Anaraki, M.; Simpson, A.J. In-vivo NMR spectroscopy: A powerful and complimentary tool for understanding environmental toxicity. Metabolites 2018, 8, 35. [CrossRef]

9. Dais, P.; Spyros, A. Nuclear magnetic resonance. In Chemical Analysis of Food: Techniques and Applications; Picó, Y., Ed.; Academic Press-Elsevier: Waltham, MA, USA, 2012; pp. 91-115. ISBN 9780123848628.

10. Bakhmutov, V.I. Practical NMR Relaxation for Chemists, 1st ed.; John Wiley \& Sons, Inc.: Chichester, UK, 2004; ISBN 0470094451.

11. Berns, A.E.; Conte, P. Effect of $\mathrm{rf}$ field inhomogeneity and sample restriction on spectral resolution of CP/MAS- 13C NMR spectra of natural organic matter. Open Magn. Reson. J. 2010, 3, 75-83. [CrossRef]

12. Berns, A.E.; Conte, P. Effect of ramp size and sample spinning speed on CPMAS ${ }^{13} \mathrm{C}$ NMR spectra of soil organic matter. Org. Geochem. 2011, 42. [CrossRef]

13. Borgia, G.C.; Brown, R.J.S.; Fantazzini, P. Uniform-penalty inversion of multiexponential decay data. J. Magn. Reson. 1998, 132, 65-77. [CrossRef] [PubMed]

14. Borgia, G.C.; Brown, R.J.S.; Fantazzini, P. Uniform-penalty inversion of multiexponential decay data: II. Data spacing, T2 data, systematic data errors, and diagnostics. J. Magn. Reson. 2000, 147, 273-285. [CrossRef] [PubMed]

15. Borgia, G.C.; Brown, R.J.S.; Fantazzini, P. Examples of marginal resolution of NMR relaxation peaks using UPEN and diagnostics. Magn. Reson. Imaging 2001, 19, 473-475. [CrossRef]

16. Bortolotti, V.; Brown, R.J.S.; Fantazzini, P.; Landi, G.; Zama, F. Uniform Penalty inversion of two-dimensional NMR relaxation data. Inverse Probl. 2017, 33, 015003. [CrossRef]

17. Bortolotti, V.; Brown, R.J.S.; Fantazzini, P.; Landi, G.; Zama, F. I2DUPEN: Improved 2DUPEN algorithm for inversion of two-dimensional NMR data. Microporous Mesoporous Mater. 2018, 269, 195-198. [CrossRef]

18. Conte, P. Environmental Applications of Fast Field-cycling NMR Relaxometry. In Field-cycling NMR Relaxometry: Instrumentation, Model Theories and Applications; Kimmich, R., Ed.; The Royal Society of Chemistry: Croydon, UK, 2019; pp. 229-254. ISBN 9781788011549. 
19. Kimmich, R. Field cycling in NMR relaxation spectroscopy: Applications in biological, chemical and polymer physics. Bull. Magn. Reson 1979, 1, 195-218.

20. Kimmich, R.; Anoardo, E. Field-cycling NMR relaxometry. Prog. Nucl. Magn. Reson. Spectrosc. 2004, 44, 257-320. [CrossRef]

21. Schaumann, G.E.; Jaeger, F.; Bayer, J. V Relaxometry in soil science. In Proceedings of the Geophysical Research Abstracts, Wien, Austria, 19-24 April 2009; Volume 11, p. EGU2009-3208-1.

22. Buchmann, C.; Meyer, M.; Schaumann, G.E. Characterization of wet aggregate stability of soils by H-NMR relaxometry. Magn. Reson. Chem. 2015, 53, 694-703. [CrossRef]

23. Schaumann, G.E.; Diehl, D.; Bertmer, M.; Jaeger, A.; Conte, P.; Alonzo, G.; Bachmann, J. Combined proton NMR wideline and NMR relaxometry to study SOM-water interactions of cation-treated soils. J. Hydrol. Hydromechanics 2013, 61, 50-63. [CrossRef]

24. Anoardo, E.; Galli, G.; Ferrante, G. Fast-Field-Cycling NMR: Applications and Instrumentation. Appl. Magn. Reson. 2001, 20, 365-404. [CrossRef]

25. Conte, P.; Bubici, S.; Palazzolo, E.; Alonzo, G. Solid-state $1 \mathrm{H}-\mathrm{NMR}$ relaxation properties of the fruit of a wild relative of eggplant at different proton Larmor frequencies. Spectrosc. Lett. 2009, 42, 235-239. [CrossRef]

26. Conte, P.; Maccotta, A.; De Pasquale, C.; Alonzo, G. Supramolecular organization of triglycerides in extra-virgin olive oils as assessed by NMR relaxometry. Fresenius Environ. Bull. 2010, 19, 2077-2082.

27. Baroni, S.; Consonni, R.; Ferrante, G.; Aime, S. Relaxometric studies for food characterization: The case of balsamic and traditional balsamic vinegars. J. Agric. Food Chem. 2009, 57, 3028-3032. [CrossRef] [PubMed]

28. Conte, P.; Mineo, V.; Bubici, S.; De Pasquale, C.; Aboud, F.; MacCotta, A.; Planeta, D.; Alonzo, G. Dynamics of pistachio oils by proton nuclear magnetic resonance relaxation dispersion. Anal. Bioanal. Chem. 2011, 400, 1443-1450. [CrossRef] [PubMed]

29. Bodart, P.R.; Rachocki, A.; Tritt-Goc, J.; Michalke, B.; Schmitt-Kopplin, P.; Karbowiak, T.; Gougeon, R.D. Quantification of manganous ions in wine by NMR relaxometry. Talanta 2020, 209, 120561. [CrossRef]

30. Conte, P.; Cuccurullo, G.; Metallo, A.; Micalizzi, A.; Cinquanta, L.; Corona, O. Comparing different processing methods in apple slice drying. Part 2 solid-state Fast Field Cycling 1H-NMR relaxation properties, shrinkage and changes in volatile compounds. Biosyst. Eng. 2019, 188, 345-354. [CrossRef]

31. Cimò, G.; Conte, P. Conformational redistribution of honey components following different storage conditions. Int. J. Spectrosc. 2015, 2015, 1-7. [CrossRef]

32. Lo Scalzo, R.; Fibiani, M.; Francese, G.; D’Alessandro, A.; Rotino, G.L.; Conte, P.; Mennella, G. Cooking influence on physico-chemical fruit characteristics of eggplant (Solanum melongena L.). Food Chem. 2016, 194. [CrossRef]

33. Ladd-Parada, M.; Povey, M.J.; Vieira, J.; Ries, M.E. Fast field cycling NMR relaxometry studies of molten and cooled cocoa butter. Mol. Phys. 2018, 117, 1020-1027. [CrossRef]

34. Uguz, S.S.; Ozvural, E.B.; Beira, M.J.; Oztop, M.H.; Sebastião, P.J. Use of NMR Relaxometry to identify frankfurters of different meat sources. Mol. Phys. 2018, 117, 1015-1019. [CrossRef]

35. Płowaś-Korus, I.; Masewicz, Ł.; Szwengiel, A.; Rachocki, A.; Baranowska, H.M.; Medycki, W. A novel method of recognizing liquefied honey. Food Chem. 2018, 245, 885-889. [CrossRef] [PubMed]

36. Tavares, M.I.B.; da Silva, E.O.; Silva, P.S.R.C.; Sebastião, P.J. The use of fast field cycling to evaluate the time domain relaxation of starches from tropical fruit seeds. Mol. Phys. 2019, 117, 1028-1033. [CrossRef]

37. Ladd Parada, M.; Povey, M.J.; Vieira, J.; Rappolt, M.; Ries, M.E. Early stages of fat crystallisation evaluated by low-field NMR and small-angle X-ray scattering. Magn. Reson. Chem. 2019, 57, 686-694. [CrossRef] [PubMed]

38. Lo Meo, P.; Mundo, F.; Terranova, S.; Conte, P.; Chillura Martino, D. water dynamics at the solid-liquid interface to unveil the textural features of synthetic nanosponges. J. Phys. Chem. B 2020, 124, 1847-1857. [CrossRef] [PubMed]

39. Ó Hógáin, D.; Davies, G.R.; Baroni, S.; Aime, S.; Lurie, D.J. The use of contrast agents with fast field-cycling magnetic resonance imaging. Phys. Med. Biol. 2011, 56, 105-115. [CrossRef]

40. Gossuin, Y.; Serhan, Z.; Sandiford, L.; Henrard, D.; Marquardsen, T.; de Rosales, R.T.M.; Sakellariou, D.; Ferrage, F. sample shuttling relaxometry of contrast agents: nmrd profiles above $1 \mathrm{~T}$ with a single device. Appl. Magn. Reson. 2016, 47, 237-246. [CrossRef]

41. Payne, K.M.; Wilds, J.M.; Carniato, F.; Botta, M.; Woods, M. On water and its effect on the performance of T1-Shortening Contrast Agents. JourIsrael J. Chem. 2017, 57, 880-888. [CrossRef] 
42. Baroni, S.; Ruggiero, M.R.; Aime, S.; Geninatti Crich, S. Exploring the tumour extracellular matrix by in vivo Fast Field Cycling relaxometry after the administration of a Gadolinium-based MRI contrast agent. Magn. Reson. Chem. 2019, 57, 845-851. [CrossRef]

43. Conte, P.; Alonzo, G. Environmental NMR: Fast-field-cycling relaxometry. eMagRes 2013, 2, $389-398$. [CrossRef]

44. Conte, P.; Schmidt, H.-P. Soil-Water Interactions Unveiled by Fast Field Cycling NMR Relaxometry; Wiley Online Library: Hoboken, NJ, USA, 2017; Volume 6.

45. Steele, R.M.; Korb, J.P.; Ferrante, G.; Bubici, S. New applications and perspectives of fast field cycling NMR relaxometry. Magn. Reson. Chem. 2016, 54, 502-509. [CrossRef]

46. Stelar Book of Applications. Available online: https://www.stelar.it/pdf/Stelar_BOOKLET-web.pdf (accessed on 13 May 2020).

47. Bleam, W.F. Soil science applications of nuclear magnetic resonance spectroscopy. Adv. Agron. 1991. [CrossRef]

48. Akitt, J.W.; McDonald, W.S. Arrangements of ligands giving low electric field gradients. J. Magn. Reson. 1984, 58, 401-412. [CrossRef]

49. Conte, P.; Nestle, N. Water dynamics in different biochar fractions. Magn. Reson. Chem. 2015, 53, 726-734. [CrossRef] [PubMed]

50. Keeler, J. Understanding NMR Spectroscopy, 1st ed.; John Wiley \& Sons, Inc.: Chichester, UK, 2010; ISBN 1119964938.

51. Bloembergen, N.; Purcell, E.M.; Pound, R.V. Relaxation effects in nuclear magnetic resonance absorption. Phys. Rev. 1948, 73, 679-712. [CrossRef]

52. Zampetoulas, V.; Lurie, D.J.; Broche, L.M. Correction of environmental magnetic fields for the acquisition of Nuclear magnetic relaxation dispersion profiles below Earth's field. J. Magn. Reson. 2017, 282, 38-46. [CrossRef] [PubMed]

53. Provencher, S.W. A constrained regularization method for inverting data represented by linear algebraic or integral equations. Comput. Phys. Commun. 1982, 27, 213-227. [CrossRef]

54. Provencher, S.W. Contin: A general purpose constrainded regularization program for inverting noisy linear algebraic and integral equations. Comput. Phys. Commun. 1982, 27, 229-242. [CrossRef]

55. Luchinat, C.; Parigi, G. Nuclear relaxometry helps designing systems for solution DNP on proteins. Appl. Magn. Reson. 2008, 34, 379-392. [CrossRef]

56. Maccotta, A.; De Pasquale, C.; Caruso, A.; Cosentino, C.; Alonzo, G.; Conte, P. Reconstruction of the environmental evolution of a Sicilian saltmarsh (Italy). Environ. Sci. Pollut. Res. 2013, 20, 4847-4858. [CrossRef]

57. Conte, P.; Ferro, V. Standardizing the use of fast-field cycling NMR relaxometry for measuring hydrological connectivity inside the soil. Magn. Reson. Chem. 2020, 58, 41-50. [CrossRef]

58. Halle, B.; Jóhannesson, H.; Venu, K. Model-Free Analysis of Stretched Relaxation Dispersions. J. Magn. Reson. 1998, 135, 1-13. [CrossRef]

59. Korb, J.P.; Whaley-Hodges, M.; Bryant, R.G. Translational diffusion of liquids at surfaces of microporous materials: Theoretical analysis of field-cycling magnetic relaxation measurements. Phys. Rev. E-Stat. Physics, Plasmas, Fluids, Relat. Interdiscip. Top. 1997, 56, 1934-1945. [CrossRef]

60. Bubici, S.; Korb, J.-P.; Kučerik, J.; Conte, P. Evaluation of the surface affinity of water in three biochars using fast field cycling NMR relaxometry. Magn. Reson. Chem. 2016, 54, 365-370. [CrossRef] [PubMed]

61. Korb, J.P. Multiscale nuclear magnetic relaxation dispersion of complex liquids in bulk and confinement. Prog. Nucl. Magn. Reson. Spectrosc. 2018, 104, 12-55. [CrossRef] [PubMed]

62. Laudicina, V.A.; de Pasquale, C.; Conte, P.; Badalucco, L.; Alonzo, G.; Palazzolo, E. Effects of afforestation with four unmixed plant species on the soil-water interactions in a semiarid Mediterranean region (Sicily, Italy). J. Soils Sediments 2012, 12, 1222-1230. [CrossRef]

63. Conte, P.; Marsala, V.; De Pasquale, C.; Bubici, S.; Valagussa, M.; Pozzi, A.; Alonzo, G. Nature of water-biochar interface interactions. GCB Bioenergy 2013, 5. [CrossRef]

64. Conte, P.; Schmidt, H.-P.; Cimò, G. Research and Application of Biochar in Europe. In Agricultural and Environmental Applications of Biochar: Advances and Barriers; Guo, M., He, Z., Uchimiya, S.M., Eds.; Soil Science Society of America, Inc.: Madison, WI, USA, 2015; pp. 409-422. ISBN 9780891189640. 
65. Schmidt, H.; Pandit, B.; Martinsen, V.; Cornelissen, G.; Conte, P.; Kammann, C. Fourfold increase in pumpkin yield in response to low-dosage root zone application of urine-enhanced biochar to a fertile tropical soil. Agriculture 2015, 5, 723-741. [CrossRef]

66. Kammann, C.I.; Schmidt, H.-P.; Messerschmidt, N.; Linsel, S.; Steffens, D.; Müller, C.; Koyro, H.-W.; Conte, P.; Stephen, J. Plant growth improvement mediated by nitrate capture in co-composted biochar. Sci. Rep. 2015, 5. [CrossRef]

67. Hagemann, N.; Joseph, S.; Schmidt, H.-P.; Kammann, C.I.; Harter, J.; Borch, T.; Young, R.B.; Varga, K.; Taherymoosavi, S.; Elliott, K.W.; et al. Organic coating on biochar explains its nutrient retention and stimulation of soil fertility. Nat. Commun. 2017, 8. [CrossRef]

68. Fang, Q.; Chen, B.; Lin, Y.; Guan, Y. Aromatic and hydrophobic surfaces of wood-derived biochar enhance perchlorate adsorption via hydrogen bonding to oxygen-containing organic groups. Environ. Sci. Technol. 2014, 48, 279-288. [CrossRef]

69. Joseph, S.; Kammann, C.I.; Shepherd, J.G.; Conte, P.; Schmidt, H.-P.; Hagemann, N.; Rich, A.M.; Marjo, C.E.; Allen, J.; Munroe, P.; et al. Microstructural and associated chemical changes during the composting of a high temperature biochar: Mechanisms for nitrate, phosphate and other nutrient retention and release. Sci. Total Environ. 2018, 618, 1210-1223. [CrossRef]

70. Baiamonte, G.; De Pasquale, C.; Marsala, V.; Cimò, G.; Alonzo, G.; Crescimanno, G.; Conte, P. Structure alteration of a sandy-clay soil by biochar amendments. J. Soils Sediments 2015, 15, 816-824. [CrossRef]

71. Juriga, M.; Šimanský, V. Effect of biochar on soil structure-review. Acta Fytotech. Zootech. 2018, 21, 11-19. [CrossRef]

72. Blas, E.D.; Almendros, G.; Sanz, J. Geoderma Molecular characterization of lipid fractions from extremely water-repellent pine and eucalyptus forest soils. Geoderma 2013, 206, 75-84. [CrossRef]

73. Diehl, D. Soil water repellency: Dynamics of heterogeneous surfaces. Colloids Surfaces A Physicochem. Eng. Asp. 2013, 432, 8-18. [CrossRef]

74. Hajnos, M.; Calka, A.; Jozefaciuk, G. Wettability of mineral soils. Geoderma 2013, 206, 63-69. [CrossRef]

75. Wang, D.; Zhang, W.; Hao, X.; Zhou, D. Transport of biochar particles in saturated granular media: Effects of pyrolysis temperature and particle size. Environ. Sci. Technol. 2013, 47, 821-828. [CrossRef]

76. Yi, S.; Witt, B.; Chiu, P.; Guo, M.; Imhoff, P. The Origin and Reversible Nature of Poultry Litter Biochar Hydrophobicity. J. Environ. Qual. 2015, 44, 963-971. [CrossRef]

77. Yi, S.; Chang, N.Y.; Imhoff, P.T. Predicting water retention of biochar-amended soil from independent measurements of biochar and soil properties. Adv. Water Resour. 2020. Accepted. [CrossRef]

78. Honegger, P.; Overbeck, V.; Strate, A.; Appelhagen, A.; Sappl, M.; Heid, E.; Schröder, C.; Ludwig, R.; Steinhauser, O. Understanding the nature of nuclear magnetic resonance relaxation by means of fast-field-cycling relaxometry and molecular dynamics simulations-the validity of relaxation models. J. Phys. Chem. Lett. 2020, 11, 2165-2170. [CrossRef]

79. Mengistu, A.G.; Mavimbela, S.S.W.; van Rensburg, L.D. Characterisation of the soil pore system in relation to its hydraulic functions in two South African aeolian soil groups. South African J. Plant Soil 2019, 36, 107-116. [CrossRef]

80. Pagliai, M.; Vignozzi, N.; Pellegrini, S. Soil structure and the effect of management practices. Soil Tillage Res. 2004, 79, 131-143. [CrossRef]

81. Pohlmeier, A.; Haber-Pohlmeier, S.; Stapf, S. A Fast Field Cycling Nuclear Magnetic Resonance Relaxometry Study of Natural Soils. Vadose Zo. J. 2009, 8, 735-742. [CrossRef]

82. Bayer, J.V.; Jaeger, F.; Schaumann, G.E. Proton nuclear magnetic resonance (NMR) relaxometry in soil science applications. Open Magn. Reson. J. 2010, 3, 15-26. [CrossRef]

83. Stingaciu, L.R.; Weihermller, L.; Haber-Pohlmeier, S.; Stapf, S.; Vereecken, H.; Pohlmeier, A. Determination of pore size distribution and hydraulic properties using nuclear magnetic resonance relaxometry: A comparative study of laboratory methods. Water Resour. Res. 2010, 46, 1-11. [CrossRef]

84. Conte, P.; Abbate, C.; Baglieri, A.; Nègre, M.; Pasquale, C.D.; Alonzo, G.; Gennari, M. Adsorption of dissolved organic matter on clay minerals as assessed by infra-red, CPMAS ${ }^{13} \mathrm{C}$ NMR spectroscopy and low field $\mathrm{T}<\mathrm{inf}>1</$ inf $>$ NMR relaxometry. Org. Geochem. 2011, 42. [CrossRef]

85. Haber-Pohlmeier, S.; Stapf, S.; Van Dusschoten, D.; Pohlmeier, A. Relaxation in a Natural Soil: Comparison of Relaxometric Imaging, T 1-T 2 Correlation and Fast-Field Cycling NMR. Open Magn. Reson. J. 2010, 3, 57-62. [CrossRef] 
86. Haber-Pohlmeier, S.; Stapf, S.; Pohlmeier, A. NMR Fast Field Cycling Relaxometry of Unsaturated Soils. Appl. Magn. Reson. 2014, 45, 1099-1115. [CrossRef]

87. Collins, A.L.; Walling, D.E.; Sichingabula, H.M.; Leeks, G.J.L. Using 137Cs measurements to quantify soil erosion and redistribution rates for areas under different land use in the Upper Kaleya River basin, southern Zambia. Geoderma 2001, 104, 299-323. [CrossRef]

88. Conte, P.; Di Stefano, C.; Ferro, V.; Laudicina, V.A.; Palazzolo, E. Assessing hydrological connectivity inside a soil by fast-field-cycling nuclear magnetic resonance relaxometry and its link to sediment delivery processes. Environ. Earth Sci. 2017, 76. [CrossRef]

89. Conte, P.; Ferro, V. Measuring hydrological connectivity inside a soil by low field nuclear magnetic resonance relaxometry. Hydrol. Process. 2018, 32. [CrossRef]

90. Marchamalo, M.; Hooke, J.M.; Sandercock, P.J. Flow and Sediment Connectivity in Semi-arid Landscapes in SE Spain: Patterns and Controls. L. Degrad. Dev. 2016, 27, 1032-1044. [CrossRef]

91. Bracken, L.J.; Wainwright, J.; Ali, G.A.; Tetzlaff, D.; Smith, M.W.; Reaney, S.M.; Roy, A.G. Concepts of hydrological connectivity: Research approaches, Pathways and future agendas. Earth-Science Rev. 2013, 119, 17-34. [CrossRef]

92. Reaney, S.M.; Bracken, L.J.; Kirkby, M.J. The importance of surface controls on overland flow connectivity in semi-arid environments: Results from a numerical experimental approach. Hydrol. Process. 2014, 28, 2116-2128. [CrossRef]

93. López-Vicente, M.; Nadal-Romero, E.; Cammeraat, E.L.H. Hydrological connectivity does change over 70 years of abandonment and afforestation in the spanish pyrenees. L. Degrad. Dev. 2017, 28, 1298-1310. [CrossRef]

94. Bracken, L.J.; Croke, J. The concept of hydrological connectivity and its contribution to understanding runoff-dominated geomorphic systems. Hydrol. Process. 2007, 21, 1749-1763. [CrossRef]

95. Wainwright, J.; Parsons, A.J.; Cooper, J.R.; Gao, P.; Gillies, J.A.; Mao, L.; Orford, J.D.; Knight, P.G. The concept of transport capacity in geomorphology. Rev. Geophys. 2015, 53, 1155-1202. [CrossRef]

96. Olson, K.R. The effects of erosion on soil pore distributions and root ramification in fine-textured Illinois soils. Soil Sci. 1988, 145, 365-373. [CrossRef]

97. Zsolnay, Á. Dissolved organic matter: Artefacts, definitions, and functions. Geoderma 2003, 113, $187-209$. [CrossRef]

98. Kopinke, F.D.; Georgi, A.; Mackenzie, K. Sorption of pyrene to dissolved humic substances and related model polymers. 1. Structure-Property correlation. Environ. Sci. Technol. Sci. Technol. 2001, 35, 2536-2542. [CrossRef]

99. Philippe, A.; Schaumann, G.E. Interactions of dissolved organic matter with natural and engineered inorganic colloids: A review. Environ. Sci. Technol. 2014, 48, 8946-8962. [CrossRef] [PubMed]

100. Kaiser, K.; Guggenberger, G.; Zech, W. Organically bound nutrients in dissolved organic matter fractions in seepage and pore water of weakly developed forest soils. Acta Hydrochim. Hydrobiol. 2001, 28, 411-419. [CrossRef]

101. Raulund-Rasmussen, K.; Borggaard, O.K.; Hansen, H.C.B.; Olsson, M. Effect of natural organic soil solutes on weathering rates of soil minerals. Eur. J. Soil Sci. 1998, 49, 397-406. [CrossRef]

102. Michalzik, B.; Kalbitz, K.; Park, J.H.; Solinger, S.; Matzner, E. Fluxes and concentrations of dissolved organic carbon and nitrogen-A synthesis for temperate forests. Biogeochemistry 2001, 52, 173-205. [CrossRef]

103. Jansen, B.; Kalbitz, K.; McDowell, W.H. Dissolved Organic Matter: Linking Soils and Aquatic Systems. Vadose Zo. J. 2014, 13. [CrossRef]

104. Gmach, M.R.; Cherubin, M.R.; Kaiser, K.; Cerri, C.E.P. Processes that influence dissolved organic matter in the soil: A review. Sci. Agric. 2020, 77, e20180164. [CrossRef]

105. Tombàcz, E. Colloidal properties of humic acids and spontaneous changes of their state under varable solution conditions. Soil Sci. 1999, 164, 814-824. [CrossRef]

106. Sutton, R.; Sposito, G. Molecular structure in soil humic substances: The new view. Environ. Sci. Technol. 2005, 39, 9009-9015. [CrossRef]

107. Benedetti, M.F.; Van Riemsdijk, W.H.; Koopal, L.K. Humic substances considered as a heterogeneous Donnan gel phase. Environ. Sci. Technol. 1996, 30, 1805-1813. [CrossRef]

108. Baigorri, R.; Fuentes, M.; González-Gaitano, G.; García-Mina, J.M. Simultaneous presence of diverse molecular patterns in humic substances in solution. J. Phys. Chem. B 2007, 111, 10577-10582. [CrossRef] 
109. Conte, P.; Kucerik, J. Water dynamics and its role in structural hysteresis of dissolved organic matter. Environ. Sci. Technol. 2016, 50. [CrossRef] [PubMed]

110. Conte, P. Effects of ions on water structure: A low-field 1H T1 NMR relaxometry approach. Magn. Reson. Chem. 2015, 53, 711-718. [CrossRef] [PubMed]

111. Palmer, N.E.; Von Wandruszka, R. Dynamic light scattering measurements of particle size development in aqueous humic materials. Anal. Bioanal. Chem. 2001, 371, 951-954. [CrossRef] [PubMed]

112. Jia, C.; You, C.; Pan, G. Effect of temperature on the sorption and desorption of perfluorooctane sulfonate on humic acid. J. Environ. Sci. 2010, 22, 355-361. [CrossRef]

113. Drastík, M.; Novák, F.; Kučerík, J. Origin of heat-induced structural changes in dissolved organic matter. Chemosphere 2013, 90, 789-795. [CrossRef]

114. Conte, P.; Piccolo, A. Conformational arrangement of dissolved humic substances. Influence of solution composition on association of humic molecules. Environ. Sci. Technol. 1999, 33. [CrossRef]

115. Marcus, Y. Thermodynamics of ion hydration and its interpretation in terms of a common model. Pure Appl. Chem. 1987, 59, 1093-1101. [CrossRef]

116. Marcus, Y. Ionic Radii in Aqueous Solutions. Chem. Rev. Rev. 1988, 88, 1475-1498. [CrossRef]

117. Plumridge, T.H.; Waigh, R.D. Water structure theory and some implications for drug design. J. Pharm. Pharmacol. 2002, 54, 1155-1179. [CrossRef]

118. Bock, C.W.; Markham, G.D.; Katz, A.K.; Glusker, J.P. The arrangement of first- and second-shell water molecules around metal ions: Effects of charge and size. Theor. Chem. Acc. 2006, 115, 100-112. [CrossRef]

119. Wiggins, P.M. Role of water in some biological processes. Microbiol. Rev. 1990, 54, 432-449. [CrossRef] [PubMed]

120. Wiggins, P.M. High and low density water in gels. Prog. Polym. Sci. 1995, 20, 1121-1163. [CrossRef]

121. Wiggins, P.M. High and low density water and resting, active and transformed cells. Cell Biol. Int. 1996, 20, 429-435. [CrossRef]

122. Wiggins, P.M. Water in complex environments such as living systems. Phys. A Stat. Mech. its Appl. 2002, 314, 485-491. [CrossRef]

123. Wiggins, P. Life depends upon two kinds of water. PLoS ONE 2008, 3, e1406. [CrossRef] [PubMed]

124. Yadav, S.; Choudhary, A.; Chandra, A. A first-principles molecular dynamics study of the solvation shell structure, vibrational spectra, polarity, and dynamics around a nitrate ion in aqueous solution. J. Phys. Chem. B 2017, 121, 9032-9044. [CrossRef] [PubMed]

125. Farashishiko, A.; Slack, J.R.; Botta, M.; Woods, M. ParaCEST agents encapsulated in Reverse Nano-Assembled Capsules (RACs): How slow molecular tumbling can quench CEST contrast. Front. Chem. 2018, 6, 1-7. [CrossRef]

126. Sharma, B.; Chandra, A. Born-oppenheimer molecular dynamics simulations of a bromate ion in water reveal its dual kosmotropic and chaotropic behavior. J. Phys. Chem. B 2018, 122, 2090-2101. [CrossRef]

127. Holtzer, A. The use of flory-huggins theory in interpreting partitioning of solutes between organic liquids and water. Biopolymers 1992, 32, 711-715. [CrossRef]

128. Holtzer, A. Does Flory-Huggins theory help in interpreting solute partitioning experiments? Biopolymers 1994, 34, 315-320. [CrossRef]

129. Huang, X.; Chaparro, J.M.; Reardon, K.F.; Zhang, R.; Shen, Q.; Vivanco, J.M. Rhizosphere interactions: Root exudates, microbes, and microbial communities 1. Botany 2014, 275, 267-275. [CrossRef]

130. Rudolph-Mohr, N.; Tötzke, C.; Kardjilov, N.; Oswald, S.E. Mapping water, oxygen, and pH dynamics in the rhizosphere of young maize roots. Zeitschrift fur Pflanzenernahrung und Bodenkd. 2017, 180, 336-346. [CrossRef]

131. Hinsinger, P.; Plassard, C.; Tang, C.; Jaillard, B. Origins of root-mediated pH changes in the rhizosphere and their responses to environmental constraints: A review. Plant Soil 2003, 248, 43-59. [CrossRef]

132. Nye, P.H. Changes of $\mathrm{pH}$ across the rhizosphere induced by roots. Plant Soil 1981, 61, 7-26. [CrossRef]

133. Wang, X.; Tang, C. The role of rhizosphere $\mathrm{pH}$ in regulating the rhizosphere priming effect and implications for the availability of soil-derived nitrogen to plants. Ann. Bot. 2018, 121, 143-151. [CrossRef]

134. Youssef, R.A.; Chino, M. Root-induced changes in the rhizosphere of plants. I. pH changes in relation to the bulk soil. Soil Sci. Plant Nutr. 1989, 35, 461-468. [CrossRef] 
135. Gallo, P.; Corradini, D.; Rovere, M. Ion hydration and structural properties of water in aqueous solutions at normal and supercooled conditions: A test of the structure making and breaking concept. Phys. Chem. Chem. Phys. 2011, 13, 19814-19822. [CrossRef]

136. Henderson, M.A. The interaction of water with solid surfaces: Fundamental aspects. Surf. Sci. Rep. 2002, 46, 1-308. [CrossRef]

137. Conte, P.; Piccolo, A.; Van Lagen, B.; Buurman, P.; Hemminga, M.A. Elemental quantitation of natural organic matter by CPMAS 13C NMR spectroscopy. Solid State Nucl. Magn. Reson. 2002, 21, 158-170. [CrossRef]

138. Ball, P. Life's matrix: Water in the cell. Cell. Mol. Biol. 2001, 47, 717-720.

139. Omta, A.W.; Kropman, M.F.; Woutersen, S.; Bakker, H.J. Negligible Effect of Ions on the Hydrogen-Bond Structure in Liquid Water. Science (80-. ) 2003, 301, 347-349. [CrossRef] [PubMed]

140. Brownstein, K.R.; Tarr, C.E. Importance of classical diffusion in NMR studies of water in biological cells. Phys. Rev. A 1979, 19, 2446-2453. [CrossRef]

(C) 2020 by the authors. Licensee MDPI, Basel, Switzerland. This article is an open access article distributed under the terms and conditions of the Creative Commons Attribution (CC BY) license (http://creativecommons.org/licenses/by/4.0/). 